\title{
WestVirginiaUniversity
}

THE RESEARCH REPOSITORY @ WVU

Graduate Theses, Dissertations, and Problem Reports

2005

\section{Real-time measurements of space potential in magnetized plasma using a baffled Langmuir probe}

Sean M. Finnegan

West Virginia University

Follow this and additional works at: https://researchrepository.wvu.edu/etd

\section{Recommended Citation}

Finnegan, Sean M., "Real-time measurements of space potential in magnetized plasma using a baffled Langmuir probe" (2005). Graduate Theses, Dissertations, and Problem Reports. 2216.

https://researchrepository.wvu.edu/etd/2216

This Thesis is protected by copyright and/or related rights. It has been brought to you by the The Research Repository @ WVU with permission from the rights-holder(s). You are free to use this Thesis in any way that is permitted by the copyright and related rights legislation that applies to your use. For other uses you must obtain permission from the rights-holder(s) directly, unless additional rights are indicated by a Creative Commons license in the record and/ or on the work itself. This Thesis has been accepted for inclusion in WVU Graduate Theses, Dissertations, and Problem Reports collection by an authorized administrator of The Research Repository @ WVU. For more information, please contact researchrepository@mail.wvu.edu. 


\title{
Real-Time Measurements of Space Potential in Magnetized Plasma using a Baffled Langmuir Probe.
}

\author{
Sean M. Finnegan
}

\author{
Thesis \\ Submitted to the Eberly College of Arts and Sciences \\ at West Virginia University \\ In Partial Fulfillment of the Requirements for \\ The Degree of Master of Science \\ in \\ Physics
}

\begin{abstract}
Mark E. Koepke, Ph.D., Chair
Earl Scime, Ph.D.

Manfred Boehm, Ph.D.

Department of Physics
\end{abstract}
Morgantown, West Virginia
2005




\title{
Abstract \\ Real-Time Measurements of Space Potential in Magnetized Plasma using a Baffled Langmuir Probe.
}

\author{
Sean M. Finnegan
}

An electrostatic probe for real-time measurements of space potential in magnetized plasma is tested in fully ionized, barium, Q-machine plasma. The tungsten wire probe tip, oriented perpendicular to the magnetic field, is partially shielded by ceramic baffles (masks). Rotation of the probe about its cylindrical axis, changes the fraction of electrons that can reach the probe tip along the magnetic field, enabling the ratio between the electron and ion saturation currents to be adjusted without changing the probe bias. When optimally shielded $\left(\left|I_{e}^{\text {sat }}\right| /\left|I_{i}^{\text {sat }}\right| \approx 1\right)$, accurate, real-time measurements of space potential can be acquired. 


\section{Acknowledgements}

I would be remiss if I did not take the time to properly acknowledge all of those who contributed to the development and completion of this thesis, for without them this work would not have been possible.

I am forever indebted to Dr. Vladimir Demidov for, among other things, having developed the original idea and design of the baffled Langmuir probe. His tutelage and guidance throughout was an invaluable asset, and I am forever grateful for his friendship. To Dr. Mark Koepke, for his ability to uncompromisingly be both an advisor and friend simultaneously. Without his assistance in the designing of the experiments, interpretation of the data, and his guidance in the completion of this document, certainly none of this would have been possible. To Mr. Eric Reynolds, for his tireless assistance in not only instructing me in the operation of the WVU Q-machine, but also for his infinite patience in answering questions concerning Matlab programming and probe construction. To the committee members, for taking the time to review this work, thank you. To the West Virginia University Physics Department faculty, under whose instruction I have attained goals I never once thought possible. To my fellow classmates, both here at West Virginia University and Dickinson College, whose friendship and support I would be lost without.

Finally, I would like to thank my family. Their unconditional love and support has never wavered. Words cannot adequately express my heart-felt gratitude for all of the sacrifices my parents have made which have brought me to this moment. Last and certainly no least, I would like to thank my grandparents George and Elizabeth Gardner, for their unselfish commitment to my education. 


\section{Table of Contents}

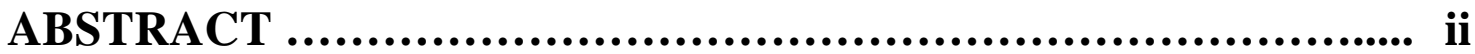

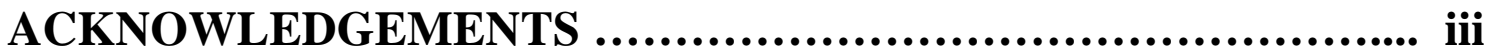

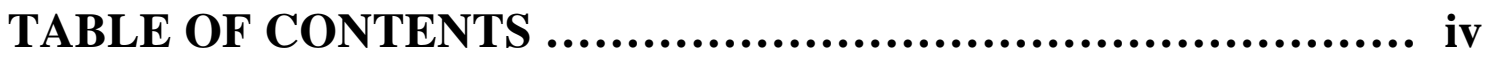

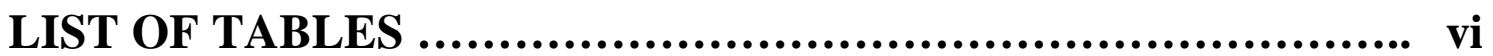

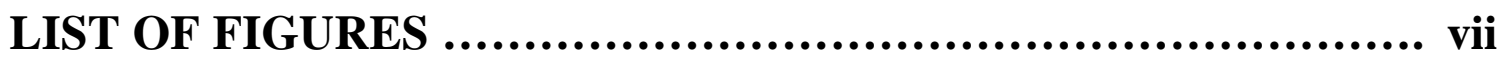

I. INTRODUCTION ...................................................... 1

A. MOTIVATION …........................................... 1

B. LANGMUIR PROBE and I-V CHARACTERISTIC ............... 2

C. EMISSIVE PROBE TECHNIQUES …........................ 3

D. ION-SENSITIVE PLUG-PROBE ............................ 4

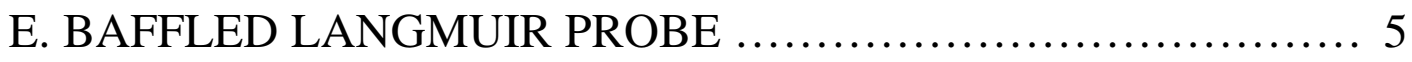

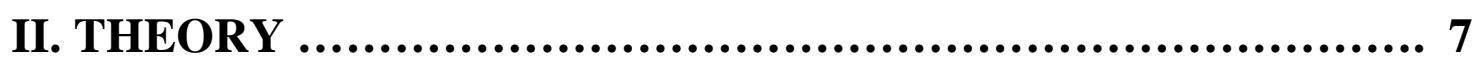

A. MODELING THE PROBE I-V CHARACTERISTIC ............ 7

B. FLOATING POTENTIAL and SPACE POTENTIAL ........... 9

C. FLOATING POTENTIAL in the PRESENCE of DRIFTING

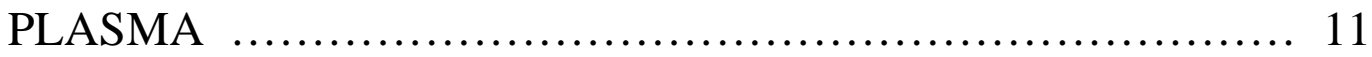

D. SPACE POTENTIAL FLUCTUATIONS .................... 15

III. EXPERIMENT ….............................................. 17

A. WVU Q-MACHINE ….................................... 17 
B. BAFFLED LANGMUIR PROBE ............................ 18

C. MEASURING CURRENT-VOLTAGE CHARACTERISTIC ..... 18

IV. EXPERIMENTAL RESULTS $\ldots \ldots \ldots \ldots \ldots \ldots \ldots \ldots \ldots \ldots \ldots \ldots \ldots . \ldots \ldots$

A. CURRENT-VOLTAGE CHARACTERISTICS ................ 20

B. FLOATING POTENTIAL $\ldots \ldots \ldots \ldots \ldots \ldots \ldots \ldots \ldots \ldots \ldots \ldots \ldots . \ldots \ldots$

V. CONCLUSIONS .................................................... 24

VI. REFERENCES $\ldots . \ldots \ldots \ldots \ldots \ldots \ldots \ldots \ldots \ldots \ldots \ldots \ldots \ldots \ldots \ldots \ldots \ldots \ldots . \ldots . \ldots . \ldots \ldots$

VII. APPENDIX A $\ldots \ldots \ldots \ldots \ldots \ldots \ldots \ldots \ldots \ldots \ldots \ldots \ldots \ldots \ldots \ldots \ldots \ldots \ldots . \ldots \ldots \ldots$

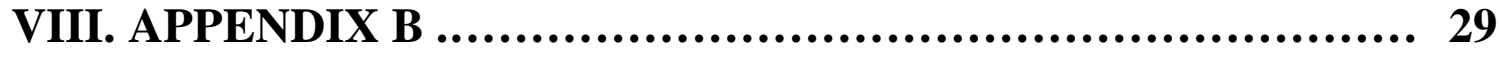

IX. TABLE $\ldots \ldots \ldots \ldots \ldots \ldots \ldots \ldots \ldots \ldots \ldots \ldots \ldots \ldots \ldots \ldots \ldots \ldots \ldots \ldots \ldots \ldots \ldots \ldots . \ldots \ldots$

X. FIGURES $\ldots \ldots \ldots \ldots \ldots \ldots \ldots \ldots \ldots \ldots \ldots \ldots \ldots \ldots \ldots \ldots \ldots \ldots \ldots \ldots \ldots \ldots \ldots \ldots \ldots$ 


\section{List of Tables}

TABLE TITLE

$\underline{\text { PAGE }}$

Table 1 Table of operational parameters for the WVU Q-machine

30 


\section{List of Figures}

\section{$\underline{\text { FIGURE TITLE }}$}

$\underline{\text { PAGE }}$

1 Typical probe current-voltage characteristic. Region $A$ is ion saturation, $B$ is the transition region, and $C$ is electron saturation.

$2 \quad$ Sketch of Katsumata probe. (1) Ceramic insulation; (2) central electrode; (3) guard electrodes.

3a Sketch of the baffled Langmuir probe. (1) Tungsten wire probe tip; (2) ceramic baffles (masks); (3) ceramic shielding.

3b Picture of the baffled Langmuir probe.

4 Numerical solutions for dimensionless coefficient $\mu=e\left(V_{S}-V_{f}\right) / T_{e}$, as a function electron drift speed. The upper curve (asterisks), is the case of zero ion drift ( $\left.v_{d i}=0\right)$. The middle curve (diamonds), represents the experimental conditions for experiments with baffled Langmuir probe $\left(v_{d i}=3 v_{T i}\right)$. The bottom curve (circles), is for bulk-plasma flow $\left(v_{d e}=v_{d i}\right)$.

5 Schematic of WVU Q-Machine [20]. Each block symbol for magnetic field coils represents a set of three coils in contact with each other, except for the outermost symbols, which represent a single coil.

6 Electric circuit diagram for measuring probe I-V characteristics. The probes voltage and current are measured/sourced by a Keithley 2400 Source Meter.

7 Model, Eqs. (3,4), of baffled probe characteristic (solid line) overlayed with measured characteristic (points) with orientation angle $\theta \approx 90^{\circ}$, at $B=3 \mathrm{kG}$. The plasma parameters obtained from the model are: $n_{o}=3 \times 10^{15} \mathrm{~m}^{-3}, T_{i}=T_{e}=0.17 \mathrm{eV}$, and $V_{S}=-7.5 \mathrm{~V}$. 
8 Model, Eqs. (3,4), of baffled probe characteristic (solid line) overlayed with measured characteristic (points) with orientation angle $\theta \approx 30^{\circ}$, at $B=3 \mathrm{kG}$. The plasma parameters obtained from the model are: $n_{o}=3 \times 10^{15} \mathrm{~m}^{-3}, T_{i}=T_{e}=0.17 \mathrm{eV}$, and $V_{S}=-7.45 \mathrm{~V}$.

9 Measured current voltage characteristics for several baffled probe orientation angles $\theta=30^{\circ}, 45^{\circ}, 60^{\circ}$, and $80^{\circ}$, at $B=3 \mathrm{kG}$. The filled circles indicate floating potential, $V_{f}$.

10 Enlarged view of the zero crossing points from Fig. 9, showing more clearly the shift in floating potential.

11 I-V characteristic obtained from baffled probe with maximally shielded probe orientation $\theta \approx 10^{\circ}$, at $B=3 \mathrm{kG}$.

12 Model, Eq. (2), of baffle probe characteristic (solid line) overlayed with the processed baffled probe characteristic of Fig. 11 (points) For probe orientation angle $\theta \approx 10^{\circ}$, at $B=3 \mathrm{kG}$. The ion temperature and space potential obtained from the model are: $T_{i}=0.19 \mathrm{eV}$, and $V_{S}=-7.48 \mathrm{~V}$.

13 Measured floating potential as the baffled probe orientation is incremented through $360^{\circ}$, at $B=3 \mathrm{kG}$.

14 Measured values of floating potential (dots) as the electron current is suppressed, at $B=3 \mathrm{kG}$. Using $T_{e} \approx 0.23 \mathrm{eV}$, the model, Eq. (7), gives the solid line, implying that the space potential is $V_{S} \approx-7.5 \mathrm{~V}$. 


\section{INTRODUCTION}

\section{A. Motivation}

Electrostatic probes are a useful diagnostic tool for measuring various DC and AC fluid and kinetic plasma quantities in magnetized and un-magnetized plasma [1-4]. The presence of waves and instabilities are a common feature of magnetized plasma. Characterizing fluctuations and fluctuation-induced transport of particle and energy flux is important to both basic plasma physics experiments, as well as high-power-densityplasma fusion experiments. Measurement of turbulence-induced particle flux requires the simultaneous measurement of oscillations in density and space potential, so that cross-correlation amplitude and phase can be determined. Similarly, experimental determination of turbulence-induced energy flux requires the simultaneous measurement of fluctuations in particle temperature and space potential. Thus, accurate DC and AC measurement of density $(n)$, particle temperature $\left(T_{e, i}\right)$ and space potential $\left(V_{s}\right)$ are necessary for characterizing plasma and its behavior. A variety of electrostatic probe designs and techniques have been developed to obtain these parameters in various plasma regimes. For accurate, real-time measurements of the unperturbed plasma parameters, the probe must be able to survive long enough for useful data to be acquired, and should not perturb the global state of the plasma [5]. Because electrostatic probes are an invasive diagnostic tool, and invariably perturb the plasma locally [6], minimization of probe-induced perturbations is desirable. 


\section{B. Langmuir Probe and I-V Characteristic}

Irving Langmuir and H. M. Mott-Smith, developed the first technique for measuring the characteristic parameters of plasma by, inserting into the plasma a small, conducting wire tip biased relative to the space potential of the plasma by an external, variable, bipolar power supply and measuring the collected probe current $[7,8]$. The measured current, $I(V)$, is commonly referred to as the current-voltage characteristic of the probe. Using a simple model for the current collected by the probe, it is possible to infer plasma parameters such as density, electron temperature, and space potential from an I-V characteristic.

A typical current-voltage characteristic is shown in Fig. 1. The various plasma parameters are obtained from three distinctly important regions of an I-V characteristic. In Fig. 1, these regions are labeled $A$ (ion saturation), $B$ (transition), and $C$ (electron saturation). In region $A$, the applied probe voltage is sufficiently negative with respect to the space potential, that practically all of the electrons are repelled away from the probe. For an electrostatic probe of radius $(R)$ being much less than the ion mean-free path $\left(\lambda_{\mathrm{i}}\right)$, the collected ion current saturates at a value that is proportional to the ion density and is relatively insensitive to the applied probe voltage. In region $B$, the width of which is approximately equal to a few (3-6 for typical Q-machine plasma) times $k_{B} T_{e} / e$, both ions and electrons are simultaneously being collected by the probe. The shape of the curve in this region is used to obtain the electron temperature. In region $C$, the applied probe voltage is sufficiently positive, relative to the space potential of the plasma, such that practically all ions are repelled from the probe surface, and the collected electron current saturates at a value that is proportional to the electron density. Models of electron and 
ion saturation can be used to determine both electron and ion densities from the measured saturation currents. The applied probe voltage at which no net current is collected, is the floating potential, $V_{f}$. As the applied probe voltage is increased positively, the probe transitions from attracting ions and repelling electrons to repelling ions and attracting electrons. The voltage at which this transition occurs is called the space potential, $V_{\mathrm{S}}$. At this voltage, the probe and the plasma are at the same potential, minimizing the Debye sheath and perturbation to the plasma. Models of electron and ion saturation can be used to infer, in real-time, the electron and ion densities from the measured saturation currents, whereas values for electron temperature, and space potential are most accurately determined by post-data-acquisition modeling of the probe's entire I-V characteristic trace. Real-time measurements of both DC and AC space potential, can be made using emissive probe techniques.

\section{Emissive Probe Techniques}

An emissive probe is an electrostatic probe consisting of a small wire loop heated ohmically to release thermo-electrons into the plasma. The basic principle of operation is that the thermo-electron current from the emissive probe into the plasma changes from zero when the probe is biased positive relative to the space potential, to a non-zero value when the probe bias is negative relative to the space potential. For applied probe voltages negative relative to the space potential, the emitted electron current flowing from the surface of the probe appears as an increase in positive current (ion collection). The most established and accurate emissive-probe technique for determining the space potential is known as the inflection-point method [9]. Identifying the voltage associated with the 
inflection point of the $I(V)$ characteristic, however, requires post acquisition analysis of the data, and is thus inconvenient for monitoring fluctuations in the space potential. Real-time measurements of space potential and its oscillations can be made by operating an emissive probe in the strong-emission regime using the floating-potential technique [10]. For emission currents of the same order of magnitude as the electron saturation current $\left(I_{e m} \approx \mathrm{O}\left(I_{e}^{\text {sat }}\right)\right)$ the measured floating potential provides a good approximation for the space potential $\left(V_{f} \approx V_{S}\right)$. Unfortunately, strong electron emission can significantly perturb the plasma [11].

\section{Ion-Sensitive Plug-Probe}

The first ion-sensitive probe to be developed was the Katsumata probe [12]. The Katsumata probe, Fig. 2, is a non-emitting, electrostatic probe, which shields electrons due to their small gyro-radius, and controls the collection of ions by positively biasing the center electrode in the cavity. Sweeping the center electrode bias enables the probe to acquire an estimate of the characteristic perpendicular ion energy, and thus a determination of the ion temperature. The most accurate use of a non-emitting electrostatic probe for real-time measurements of space potential and its oscillations has been demonstrated only recently [13], and is based on almost complete suppression of collected electron current [14]. The suppression is achieved by using shields (perpendicular masks) at the ends of a magnetic field aligned probe tip. For non-emitting probes, as the measured electron saturation current is reduced, the floating potential shifts toward the space potential, such that, for $I_{e}^{\text {sat }} \approx I_{i}^{\text {sat }}$, the floating potential approximates the space potential, $V_{f} \approx V_{S}$. Since the plug-probe is floating and non-emitting, 
perturbations to the plasma are significantly decreased, allowing for accurate real-time DC and AC measurements of the space potential. The plug-probe method has been shown experimentally and theoretically, to be valid for $T_{e} \gg T_{i}$ [13]. One potential drawback to the use of a plug-probe for monitoring space potential, however, is that the probe's cylindrical axis requires precise alignment with the magnetic field in order to achieve optimal shielding. Because shielded probe techniques have demonstrated the ability to make accurate real-time measurements of both DC and AC space potential, while minimizing perturbation to the local plasma conditions, it is desirable to develop a shielded probe technique for the monitoring of both DC and AC space potential for the case of comparable electron and ion temperatures $\left(T_{e} \approx T_{i}\right)$, a case for which the plug probe has not been tested.

\section{E. Baffled Langmuir Probe}

Like both the Katsumata and plug probes, the baffled Langmuir probe [15] is a shielded, non-emitting electrostatic probe. The baffled Langmuir probe is used for accurate real-time monitoring of $\mathrm{DC}$ and $\mathrm{AC}$ space potential. The probe consists of a tungsten wire probe tip, partially shielded by $\mathrm{Al}_{2} \mathrm{O}_{3}$ ceramic baffles (masks), as seen in Figs. 3a and 3b. Unlike the Katsumata probe, the baffled probe suppresses collected electron current with rotatable masks, and unlike the $T_{e} \gg T_{i}$ conditions for which the plug-probe was designed, the $T_{e} \approx T_{i}$ conditions significantly increase the ion collection relative to the electrons and, hence, the precise alignment of the shields relative to the magnetic field axis is not critical. The probe is oriented perpendicular to the direction of the magnetic field, unlike the parallel orientation of the plug probe. Similar to the plug 
probe, the baffled probe works under the condition that the distance from the surface of the probe tip to the outer surface of the baffles, $d$, satisfies the relation $\rho_{L e}<<\leq \rho_{L i}$, where $\rho_{L e, L i}$ are the electron and ion Larmor radii respectively. Rotation of the probe about its cylindrical axis enables the ratio between the electron and ion saturation currents to be adjusted without changing the probe bias or shield size. The rotational position of the baffles that is associated with optimal shielding of electrons from the probe surface is referred to as the closed or " $0^{\circ}$ " orientation. Likewise, the rotational position of the baffles that is associated with negligible shielding of electrons from the probe surface is referred to as the open or " $90^{\circ}$ " orientation. The ability to tolerate large baffles and smaller collection area, relaxes the magnetic field alignment precision. This thesis documents that accurate real-time DC measurement of the space potential can be made with the baffled Langmuir probe in barium plasma with $T_{e} \approx T_{i}$.

In this thesis, real-time DC measurements of space potential obtained using a baffled Langmuir probe are reported. The baffled Langmuir probe design was originally developed by Dr. Vladimir Demidov, and has since been modified by both Dr. Demidov and Dr. Mark Koepke. The construction of the baffled probe, as well as the acquisition of the experimental data presented in this thesis was done by myself here at West Virginia University. Analysis of the data was conducted by Dr. Demidov, Dr. Koepke, and myself, while I alone evaluated all of the equations, and produced all of the figures contained within this document. 


\section{THEORY}

\section{A. Modeling the Probe I-V Characteristic}

Extracting the information about the plasma condition from the currentvoltage characteristics obtained with the baffled probe requires an accurate modeling of the $I(V)$ characteristic trace. The electron current collected by the probe can be modeled using a diffusive probe theory [16]. For a cylindrical probe of radius $R$ and length $L$, such that $L>>2 R$ and $L / R<<2 \sqrt{1+\left(\Omega_{e} / v_{e n}\right)^{2}}$, oriented perpendicular to the magnetic field direction, in fully ionized, strongly magnetized $\left(v_{e n} / \Omega_{e}<<1\right)$ plasma, the transition part of the current voltage characteristic for electron current can be modeled using [16]

$$
e V=-T_{e} \ln \left[\frac{\sqrt{8 \pi} n_{o} e R^{2} \sqrt{T_{e} / m_{e}}\left(1-I_{e} / I_{e}^{s a t}\right)}{I_{e}}\right]-T_{i} \ln \left(1-I_{e} / I_{e}^{s a t}\right),
$$

where, $V$ is the applied probe voltage relative to the space potential, $V_{S}$. Similarly, the ion current in the transition region can be modeled using [16]

$$
e V=T_{i} \ln \left[\frac{\sqrt{2} \pi n_{o} e R L \sqrt{T_{i} / m_{i}}\left(1-I_{i} / I_{i}^{\text {sat }}\right)}{I_{i}}\right]+T_{e} \ln \left(1-I_{i} / I_{i}^{\text {sat }}\right) .
$$

Equations (1) and (2) are directly applicable when electrons are not being shielded from the probe surface $\left(\theta=90^{\circ}\right)$. For other rotation angles $(\theta)$, an unknown geometrical factor should be included in the denominator of the first term in both equations (1) and (2). We have assumed this factor to be the ratio $I_{e, 0^{\circ}}^{s a t} / I_{e, \theta}^{s a t}$ for corresponding $\theta$. This assumption gives consistent results for a wide range of measured $I_{e}^{\text {sat }}$, assuming that $I_{e, \theta}^{s a t} \neq 0$. Equations (1) and (2) are solved for $I_{e}$ and $I_{i}$ respectively in appendix A, to 
obtain an analytical expression for $I(V)$. Since we have chosen to define the ion saturation current as a positive value, we represent the entire characteristic with the expression

$$
I(V)=I_{e}-I_{i}
$$

where the collected electron current $\left(I_{e}\right)$ and collected ion current $\left(I_{i}\right)$ are

$$
I_{e}=I_{e}^{s a t}+\frac{\left(I_{e}^{s a t}\right)^{2}}{\sqrt{32 \pi} n_{o} e R^{2} v_{i e}} e^{-\frac{e V}{T}}-I_{e}^{s a t} \sqrt{\frac{I_{e}^{s a t}}{\sqrt{8 \pi} n_{o} e R^{2} v_{T e}}} e^{-\frac{e V}{2 T}}\left[1+\frac{I_{e}^{s a t}}{\sqrt{128 \pi} n_{o} e R^{2} v_{T e}} e^{-\frac{e V}{T}}\right]^{1 / 2},
$$

and

$$
I_{i}=I_{i}^{s a t}+\frac{\left(I_{i}^{s a t}\right)^{2}}{\sqrt{8} \pi n_{o} e R L v_{T i}} e^{\frac{e V}{T}}-I_{i}^{s a t} \sqrt{\frac{I_{i}^{s a t}}{\sqrt{2} \pi n_{o} e R L v_{T i}}} e^{\frac{e V}{2 T}}\left[1+\frac{I_{i}^{s a t}}{\sqrt{32 \pi} n_{o} e R L v_{T i}} e^{\frac{e V}{T}}\right]^{1 / 2} .
$$

Here, $v_{T e}=\sqrt{T_{e} / m_{e}}$ is the electron thermal speed and $v_{T i}=\sqrt{T_{i} / m_{i}}$ is the ion thermal speed, with $T_{e}$ and $T_{i}$ in energy units.

The equilibrium density is calculated indirectly by comparing measurements of the electron saturation current for open $\left(\theta=90^{\circ}\right)$ and $\operatorname{closed}\left(\theta=0^{\circ}\right)$ probe orientations. When the probe is maximally shielded $\left(\theta=0^{\circ}\right)$, the electron saturation current is reduced by a multiplicative factor of $v_{e n} / \Omega_{e}$ to correct for cross-field diffusive effects $\left(v_{e n}\right.$ is the electron-neutral collision frequency, and $\Omega_{e}$ is the electron gyrofrequency). The equation for the density takes the form

$$
n_{o}=\left(3.8 \times 10^{21} \frac{1}{\mathrm{~m}^{3} \cdot \mathrm{kG} \cdot \mathrm{eV}^{3 / 2}}\right) B T_{e}^{3 / 2} \frac{I_{e, 0^{\circ}}^{s a t}}{I_{e, 90^{\circ}}^{s a t}}
$$


Here, $n_{o}$ is in $\mathrm{m}^{-3}, T_{e}$ is in $\mathrm{eV}$, and $B$ is in $\mathrm{kG}$. The derivation of Eq. (4) is located in appendix B.

\section{B. Floating Potential and Space Potential}

Many techniques for determining the space potential from an I-V characteristic are dependent upon probe type as well as operational regime. Specifically, we are concerned with the "knee-point" and "inflection point" techniques used for cylindrical, non-heated probes in magnetized, collisionless to weakly collisional plasma. The most common method is to use the electron saturation "knee" of the characteristic trace as the space potential reference. Conceptually, the "knee" corresponds, within $k_{B} T_{e} / e$, to the point where the applied probe voltage is equivalent to the space potential, because the current saturates at voltages above the space potential and decreases exponentially at voltages below the space potential. In a collisionless regime, the probe bias corresponding to the local maximum of $d I_{e} / d V$, when $d^{2} I_{e} / d V^{2}$ changes sign, should coincide within $k_{B} T_{e} / e$ of the space potential. In general, however, this technique will only provide an approximation of the space potential due to effects such as large amplitude $\left(\sim k_{B} T_{e} / e\right)$ fluctuations in space potential, and finite resistivity of the plasma [17]. These methods can give a good approximation of the space potential, but require post data acquisition analysis. As discussed in the introduction, accurate, real-time measurement of space potential can be made with an emissive probe, if one can tolerate the perturbation to the plasma and possible changes in the regime (strong, intermediate, weak) of emission. 
Emissive probe techniques allow us to acquire instantaneous measurements of the space potential. Heating a probe with sufficient current, such that thermo-electrons are emitted into the plasma, leads to zero electric field and space-charge limited current near the probe surface. The formula for the floating potential of a heated probe (valid only for applied probe voltages below the space potential, $V_{b}<V_{S}$, and Maxwellian plasma) is

$$
V_{f}=V_{S}-\frac{\mu}{e} T_{e}
$$

Here, $V_{S}$ is the space potential, $V_{f}$ is the floating potential, $T_{e}$ is the temperature of the bulk plasma electrons, and $\mu$ is a constant that depends on the values of ion and electron collection as well as the value of the electron emission. We can see that the space potential is shifted, by a factor that is proportional to the electron temperature $T_{e}$, from the floating potential. This constant $\mu$, is expressed in terms of the electron saturation current $\left(I_{e}^{\text {sat }}\right)$, the ion saturation current $\left(I_{i}^{\text {sat }}\right)$, and the emission current $\left(I_{e m}\right)$ of thermoelectrons into the plasma

$$
\mu=\ln \left[\frac{I_{e}^{s a t}}{I_{i}^{s a t}+I_{e m}}\right]
$$

For significantly large emission current $\left(I_{e m} \approx I_{e}^{\text {sat }}\right)$, assuming $I_{i}^{\text {sat }} \ll I_{e}^{\text {sat }}$, the coefficient $\mu$ approaches zero, and thus the floating potential approaches the space potential. Unfortunately, this significantly disturbs the local plasma conditions near the probe surface [11]. Equations (5) and (6) are also directly applicable to electrostatic probes which are non-emitting. Setting the emission current to zero $\left(I_{e m}=0\right)$, and substituting Eq. (6) into Eq. (5), yields 


$$
V_{s}=V_{f}+\frac{T_{e}}{e} \ln \left[\frac{I_{e}^{s a t}}{I_{i}^{s a t}}\right]
$$

Equation (7) shows how the floating potential is shifted from the space potential (associated with the "knee" of the I-V characteristic) by a factor proportional to the electron temperature, $T_{e}$. It is also evident that, as the electron saturation current approaches the ion saturation current, the floating potential approaches the space potential. Thus, monitoring the floating potential when $I_{e}^{\text {sat }} \approx I_{i}^{\text {sat }}$, provides an accurate measurement of the instantaneous space potential, without significantly perturbing the plasma surrounding the probe. This is the premise on which the baffled Langmuir probe is designed. As discussed in section I.E, when the baffled Langmuir probe is rotated about its cylindrical axis to an orientation such that the electron current is reduced to $I_{e}^{s a t} \approx I_{i}^{s a t}$, the measured floating potential will correspond to the instantaneous space potential.

\section{Floating Potential in the Presence of Drifting Plasma}

Analysis of probe characteristics from a plasma with a single drifting species, or bulk-plasma flow, using stationary probe theories may lead to errors in the estimates of space potential and temperature $[8,18]$.

For simplicity, let us consider the baffled Langmuir probe in the open position (not shielding electrons) as a one-sided, perfectly absorbing, non-emitting, planar probe with the area normal of its probe face oriented parallel to the $z$ axis. Restricting our analysis to the retarding field region (range of repelling voltages), only those particles of

species a, with $(1 / 2) m_{\alpha} v_{z}{ }^{2}+q_{\alpha} V_{S} \geq q_{\alpha} V_{b}$, where $V_{b}$ is the applied probe bias, will be 
collected at the probe surface. The total current density collected at the surface of the probe is the sum of the current densities from all contributing plasma species a.

$$
\vec{J}=\sum_{\alpha} \vec{J}_{\alpha}
$$

The current density at the surface of the probe for species a is given by,

$$
\vec{J}_{\alpha}=\hat{z} q_{\alpha} \int_{-\infty}^{\infty} d v_{x} \int_{-\infty}^{\infty} d v_{y} \int_{v_{\min }}^{\infty} d v_{z} v_{z} f_{\alpha}\left(v_{x}, v_{y}, v_{z}\right)
$$

Where $v_{\min }=-\sqrt{2 q_{\alpha} V_{r} / m_{\alpha}}$. Assuming that the particle distribution function has the form of a drifting Maxwellian velocity distribution with a single temperature,

$$
f_{\alpha}\left(v_{x}, v_{y}, v_{z}\right)=\frac{n_{0}}{\pi^{2 / 2} v_{T \alpha}^{2}} \exp \left[-\frac{\left(v_{x}-v_{d x}\right)^{2}+\left(v_{y}-v_{d y}\right)^{2}+\left(v_{z}-v_{d z}\right)^{2}}{v_{T \alpha}^{2}}\right],
$$

the current density for species a collected at the surface of the probe is [17]

$$
\begin{array}{r}
J_{\alpha}=\frac{q_{\alpha} n_{0} v_{T \alpha}}{2 \sqrt{\pi}}\left\{\exp \left[-\left(\sqrt{\frac{q_{\alpha}\left(V_{b}-V_{S}\right)}{T_{\alpha}}}-\frac{v_{d \alpha}}{v_{T \alpha}}\right)^{2}\right]+\ldots\right. \\
\left.\ldots \sqrt{\pi} \frac{v_{d \alpha}}{v_{T \alpha}} \operatorname{erfc}\left[\sqrt{\frac{q_{\alpha}\left(V_{b}-V_{S}\right)}{T_{\alpha}}}-\frac{v_{d \alpha}}{v_{T \alpha}}\right]\right\} .
\end{array}
$$

Here, temperature $T_{\alpha}$ is in energy units, $v_{T \alpha}=\sqrt{2 T_{\alpha} / m_{\alpha}}$ is the thermal speed, $v_{d \alpha}$ is the drift speed, and $\operatorname{erfc}[x]$ is the complimentary error function. In a plasma with no drifting species $\left(v_{d \alpha}=0\right)$, the collected current contribution from species a, has the familiar exponential form,

$$
J_{\alpha}=\frac{q_{\alpha} n_{0} v_{T \alpha}}{2 \sqrt{\pi}} \exp \left[-\frac{q_{\alpha}\left(V_{b}-V_{S}\right)}{T_{\alpha}}\right] .
$$


When the probe is biased at the space potential $\left(V_{b}=V_{S}\right)$, all motion to the probe is thermal, and the current density is,

$$
J_{\alpha}=\frac{q_{\alpha} n_{0} v_{T \alpha}}{2 \sqrt{\pi}}
$$

For a drifting species, the contribution to the current density at the probe surface when the probe is biased at the space potential is,

$$
J_{\alpha}=\frac{q_{\alpha} n_{0} v_{T \alpha}}{2 \sqrt{\pi}}\left\{\exp \left[-\left(\frac{v_{d \alpha}}{v_{T \alpha}}\right)^{2}\right]+\sqrt{\pi} \frac{v_{d \alpha}}{v_{T \alpha}} \operatorname{erfc}\left[-\frac{v_{d \alpha}}{v_{T \alpha}}\right]\right\}
$$

When the applied probe bias is equal to the floating potential $\left(V_{b}=V_{f}\right)$, the total current density collected at the surface of the probe is zero $\left(\vec{J}=\sum_{\alpha} \vec{J}_{\alpha}=0\right)$. This means that for a two species plasma of electrons and ions, the electron current is equal to the ion current at the surface of the probe $\left(-J_{e}\left(V_{b}=V_{f}\right)=J_{i}\left(V_{b}=V_{f}\right)\right)$. In plasmas with electron and ion drift speeds satisfying the inequality,

$$
\begin{aligned}
\left\{\exp \left[-\left(\frac{v_{d e}}{v_{T e}}\right)^{2}\right]+\right. & \left.\sqrt{\pi} \frac{v_{d e}}{v_{T e}} \operatorname{erfc}\left[-\frac{v_{d e}}{v_{T e}}\right]\right\}>\ldots \\
& \cdots \sqrt{\frac{m_{e}}{m_{i}}}\left\{\exp \left[-\left(\frac{v_{d i}}{v_{T i}}\right)^{2}\right]+\sqrt{\pi} \frac{v_{d i}}{v_{T i}} \operatorname{erfc}\left[-\frac{v_{d i}}{v_{T i}}\right]\right\} .
\end{aligned}
$$

the current collected at the surface of the probe is dominated by the electron current. Thus, the floating potential is in the retarding field region only for electrons $\left(V_{b}-V_{S}<0\right)$. This means that Eq. (11) is not valid for ions when $V_{b}=V_{f}$. In order to estimate the effect of particle drifts on the shift between floating potential and space potential $\left(V_{f}-V_{S}\right)$, we assume that the ion current saturates in the retarding field region 
for electrons at a value approximately equal to the current density collected at the space potential.

$$
J_{i}\left(V_{b}<V_{S}\right) \approx \frac{e n_{0} v_{T i}}{2 \sqrt{\pi}}\left\{\exp \left[-\left(\frac{v_{d i}}{v_{T i}}\right)^{2}\right]+\sqrt{\pi} \frac{v_{d i}}{v_{T i}} \operatorname{erfc}\left[-\frac{v_{d i}}{v_{T i}}\right]\right\}
$$

Equation (5) is used to express the electron current density $J_{e}$ in terms of the dimensionless coefficient $\mu$ for $V_{b}=V_{f}$.

$$
J_{e}\left(V_{b}=V_{f}\right)=\frac{-e n_{0} v_{T e}}{2 \sqrt{\pi}}\left\{\exp \left[-\left(\sqrt{\mu}-\frac{v_{d e}}{v_{T e}}\right)^{2}\right]+\sqrt{\pi} \frac{v_{d e}}{v_{T e}} \operatorname{erfc}\left[\sqrt{\mu}-\frac{v_{d e}}{v_{T e}}\right]\right\}
$$

When there are no particle drifts $\left(v_{d e}=v_{d i}=0\right), \mu$ is easily determined by equating equations (16) and (17).

$$
\mu=\ln \left(\sqrt{\frac{m_{i}}{m_{e}}}\right)
$$

Here, we have assumed that the electrons and ions have the same temperature $\left(T_{e}=T_{i}=T\right)$. For finite particle drifts $\left(v_{d e, i} \neq 0\right)$ however, the functional dependence of the current density on the complimentary error function makes obtaining an analytical solution for $\mu$ intractable. Instead, equations (16) and (17) are equated and solved numerically for the dimensionless coefficient $\mu$ as a function of particle drift speed.

Figure 4 shows $\mu$ as a function of normalized electron drift speed for three cases of ion drift speed. The values of $\mu$ plotted in Fig. 4, are for a barium plasma with equivalent electron and ion temperatures $T_{e}=T_{i}=0.2 \mathrm{eV}$. The upper curve in Fig. 4 (asterisks), is the case of zero ion drift $\left(v_{d i}=0\right)$. It is clear from the upper curve that, an increase in electron drift speed causes the floating potential to become more negative 
relative to the space potential, increasing the relative shift between the floating potential and the space potential. The bottom curve in Fig. 4 (circles), is for bulk-plasma flow $\left(v_{d e}=v_{d i}\right)$ in the reference frame of the probe. It is clear that as the bulk flow speed is increased, the floating potential shifts towards the space potential. This is easily understood if we consider the case when the bulk flow is much larger than the electron thermal speed. When the probe is biased at the space potential, there are no attracting or retarding fields surrounding the probe surface. So, as the bulk drift becomes larger, the total current collected at the surface of the probe approaches zero, and thus the floating potential approaches the space potential. The middle curve in Fig. 4 (diamonds), represents an ion drift that is a factor of three larger than its thermal speed $\left(v_{d i}=3 v_{T i}\right)$. This is the case for the experiments conducted with the baffled Langmuir probe in the WVU Q-machine. When the probe is oriented in a closed position, the collected current at the surface of the probe is the result of particle motion perpendicular to the magnetic field, and is thus unaffected by the drifting of a species parallel to the magnetic field. For open probe orientations however, electrons drifting parallel to the magnetic field will cause the floating potential to shift negatively with respect to the space potential increasing the value of the dimensionless coefficient $\mu$.

\section{Space Potential Fluctuations}

Unfortunately there is no theory for calculating the collected probe current in the case of diffusive motion of electrons, and weakly collisional motion of ions. We can, however, use any of the diffusive models to estimate the role of various oscillations on our probe measurements. In the presence of space potential fluctuations, there can also 
exist fluctuations of temperature $\left(\tilde{T}_{e}\right.$ and $\left.\tilde{T}_{i}\right)$ that cause $V_{f}$ and $\tilde{V}_{f}$ to deviate from $V_{S}$ and $\tilde{V}_{S}$. A linear relationship between $\tilde{V}_{f}, \tilde{V}_{S}, \tilde{T}_{e}$, and $\tilde{T}_{i}$ is expected for small oscillations.

$$
\tilde{V}_{S}=\tilde{V}_{f}+\frac{\mu_{e}\left(T_{e}, T_{i}\right)}{e} \tilde{T}_{e}+\frac{\mu_{i}\left(T_{i}, T_{e}\right)}{e} \tilde{T}_{i}
$$

We have assumed that the flight time of charged particles to the probe from outside the diffusive volume is much less that the period of oscillations, ensuring that the coefficient normally appearing before $\tilde{V}_{S}$ in Eq. (19) is unity. Optimally shielding the baffled probe, so that $I_{e}^{\text {sat }} \approx I_{i}^{\text {sat }}$, causes the coefficients $\mu_{e}$ and $\mu_{i}$ to vanish, allowing fluctuations in space potential to be directly measured while the probe is floating.

$$
\tilde{V}_{S} \approx \tilde{V}_{f}
$$




\section{EXPERIMENT}

\section{A. WVU Q-Machine}

The baffled Langmuir probe, was tested in plasma produced in the West Virginia University Q-machine [19]. A diagram of the WVU Q-machine is given in Fig. 5. The linear stainless steel vacuum chamber is $25 \mathrm{~cm}$ in outer diameter and 4 meters in length. The chamber is aligned axially with 41 electromagnets that surround the vacuum chamber. There are 56 ports located on the chamber, of which 48 can be used for diagnostic access. The diagnostic ports are separated by $26.5 \mathrm{~cm}$ axially and $90^{\circ}$ azimuthally. The electromagnets are capable of producing homogeneous, axial magnetic fields up to $4 \mathrm{kG}$ within the chamber. Located at both ends of the machine are the plasma sources. The barium plasma is produced by contact ionization of barium atoms showered onto the surface of each source's hot plate. The barium plasma is neutralized by thermionic electrons emitted from the surface of the source hot plate. In our experiments, only the source located on the north end of the machine was used for plasma production. The south source served as an unheated terminating electrode. The plasma column produced by a source with a 3.1-inch hot plate is $3 \mathrm{~m}$ in length and approximately $8 \mathrm{~cm}$ in diameter. Typical plasma parameters for the WVU Q-machine are listed in Table 1. The baffled Langmuir probe was inserted into the machine exactly halfway between the plasma column ends. 


\section{B. Baffled Langmuir Probe}

A diagram and photograph of the baffled Langmuir probe are located in Figs. 3a and 3b. The probe consists of a $2 \%$ thoriated tungsten wire tip ( $2.54 \mathrm{~mm}$ diameter), and two coaxial $\mathrm{Al}_{2} \mathrm{O}_{3}$ ceramic shielding cylinders. The outer ceramic cylinder $(8 \mathrm{~mm}$ outer diameter, $5 \mathrm{~mm}$ inner diameter $)$ has a slot $(2.5 \mathrm{~mm}$ wide $)$ that is parallel to the cylindrical axis, creating two baffles (masks), each $7.6 \mathrm{~mm}$ wide and $7 \mathrm{~mm}$ in height. The inner coaxial ceramic cylinder ( $4.8 \mathrm{~mm}$ outer diameter, $3 \mathrm{~mm}$ inner diameter $)$ is used to separate the probe tip from the baffles. The exposed probe tip is $2 \mathrm{~mm}$ in diameter and $10 \mathrm{~mm}$ in length, which presents a cross-sectional area of $20 \mathrm{~mm}^{2}$. The entire probe construction is held fixed by a macor probe stem adapter, which connects the probe to the probe shaft. Thus, the entire probe shaft must be rotated in order for the baffle orientation to be adjusted relative to the direction of the magnetic field.

\section{Measuring Current-Voltage Characteristic}

The probe is connected to a computer controlled power supply by a $25 \mathrm{ft}$ RG-58 cable with BNC connectors, Fig. 6. The power supply is controlled using a Lab-View, virtual user interface written by Eric W. Reynolds. Measurements of the I-V characteristic were made by sweeping the applied probe voltage from $-15 \mathrm{~V}$ to $15 \mathrm{~V}$ relative to the floating potential. The current collected by the probe was measured by the source-meter, relayed to the computer, and recorded along with the voltage applied to the probe. Error in the measurement of collected probe current, results not only from plasma noise, but also from the reading rate of the source meter. For these experiments, the 
integration time of the A/D converter was set to 0.1 PLC (power line cycles: $1 / 60 \mathrm{sec}$ ). The resulting error in measured current, contributed by the source meter is $I \pm 0.001 \mu \mathrm{A}$. 


\section{EXPERIMENTAL RESULTS}

\section{A. Current-Voltage Characteristic}

Current-voltage characteristic measurements were made at $10^{\circ}$ intervals for probe orientation angles from $\theta=0^{\circ}$ to $\theta=360^{\circ}$. A typical I-V characteristic for the baffled Langmuir probe, when electrons are not being shielded from the probe surface $\left(\theta=90^{\circ}, 270^{\circ}\right.$, etc. $)$, is shown in Fig. 7. For such orientations, the probe acts as an ordinary, unshielded Langmuir probe. The plasma parameters obtained using an iterative least squares fitting routine on the I-V characteristic using Eq. (3) are $T_{e} \approx T_{i}=0.17 \mathrm{eV}$, and $V_{s}=-7.5 \mathrm{~V}$ relative to ground. Equation (4) gives the density as $n_{o}=3 \times 10^{15} \mathrm{~m}^{-3}$. The measured electron saturation current is much larger than the ion saturation current, enabling the space potential to be estimated using the electron saturation "knee".

When the probe is rotated such that the electrons are optimally shielded $\left(\left|I_{e}^{\text {sat }}\right| /\left|I_{i}^{\text {sat }}\right| \approx 1\right)$ from the probe tip $\left(\theta \approx 30^{\circ}, 170^{\circ}, 340^{\circ}\right.$, etc. $)$, the magnitude of the electron saturation current is approximately equal to the magnitude of the ion saturation current, as shown in Fig. 8. The model of the characteristic gives approximately identical values for the plasma parameters obtained from the model of the $\theta=90^{\circ}$ characteristic. We can see in Fig. 8 that the floating potential has shifted positively by approximately 1.5 V from its measured value for $\theta=90^{\circ}$. Values of electron temperature, floating potential, and space potential obtained from the I-V characteristic for $\theta=90^{\circ}$ are used to calculate $\mu$, which was typically between 5 and 6 for the experiments reported here. In the case of equivalent magnitudes of electron and ion saturation currents, the right hand 
side of Eq. (7) reduces to the floating potential. In this case, the floating potential measured by a closed baffled Langmuir probe is approximately equivalent to the space potential. Figure 8, shows that the floating potential closely matches the value of the space potential obtained from the least squares fit of the $I(V)$ characteristic for the unshielded probe orientation.

The suppression of electron current, and the shift in floating potential toward the space potential are clearly visible in Fig. 9 as the probe is rotated from an open orientation to a closed orientation. Figure 9, is an overlay of current-voltage characteristic traces for four different probe rotations. The open probe has the largest electron saturation current, whereas the closed probe has the smallest value of electron saturation. It is clear that the floating potential (filled circles) shifts positively as the probe is rotated toward the closed position. When the probe is optimally shielded from electrons (closed), the floating potential (furthest right filled circle) lies directly beneath the electron saturation "knee" of the open probe characteristic. Further shielding from electrons (maximally shielded) shifts the floating potential to the positive side of the space potential. This shifting of the floating potential toward the plasma potential is accurately predicted by Eq. (7).

To see this shifting of floating potential more clearly, Fig. 9 has been magnified around the bias voltage axis, Fig. 10. As more electrons are shielded from the probe surface, the rate at which the floating potential approached the space potential increases for the four cases illustrated. This effect is the direct result of the ratios of saturation currents being the argument of the natural logarithm in Eq. (7). It is clear in Fig. 10 that, as the probe is closed, the ion saturation current is also reduced. When the probe is 
rotated into a closed position, only those ions with $\rho_{L i}>d$ (or $v_{\perp}>d \Omega_{i}$ ) will make it to the surface of the probe, thus reducing the number of ions collected by the probe for a given applied voltage. Similarly, the baffles also place a restriction on the acceptance angle for ions with a given pitch angle, such that only ions satisfying $\theta_{\text {pitch }}>\theta_{\text {accept }}^{\min }$ $\left(\theta_{\text {accept }}^{\min }\right.$ is shown in Fig. 2a) will be collected by the probe. This too will cause a reduction in measured ion saturation current. As the probe is rotated through $360^{\circ}$, the range of pitch angles of collected ions is restricted in a modulated fashion.

For maximally shielded $\left(\left|I_{e}^{\text {sat }}\right| /\left|I_{i}^{\text {sat }}\right|<1\right)$ probe orientations $\left(\theta \approx 10^{\circ}, 350^{\circ}\right)$, (Fig. 11) the probe operates on the same shielding principle as a Katsumata probe (electrons completely shielded from probe electrode), providing an accurate measurement of the ion temperature. In Fig. 11, the electron current has been suppressed to the point where $I_{e}^{\text {sat }} / I_{i}^{\text {sat }} \approx 0.1$. To model the characteristic in Fig. 11, a best fit straight line to the electron saturation was determined and then subtracted from the entire trace. This artificially set the electron saturation current to zero in the processed trace, while producing negligible change in the ion saturation and transition regions. A least squares fit of the trace using Eq. (2), Fig. 12, provides values for ion temperature and space potential: $T_{i}=0.19 \mathrm{eV}, V_{s}=-7.48 \mathrm{~V}$. The value of ion temperature obtained with the baffled probe, was compared with measurements of ion temperature obtained using laserinduced florescence (LIF) measurements of the unperturbed ion velocity distribution function taken by Eric W. Reynolds under similar operational conditions. The ion temperature, as measured with LIF, was consistently $T_{i} \approx 0.18 \pm \delta T_{ \pm} \mathrm{eV}$. The error, $\delta T_{ \pm}$, associated with the LIF measured ion temperature is dependent upon the signal to noise 
ratio, and is approximately: $\delta T_{+}=0.01 \mathrm{eV}, \delta T_{-}=0.02 \mathrm{eV}$, for this measurement. The relatively good agreement between the ion temperature as measured by the baffled Langmuir probe, and the ion temperature as measured using LIF, is convincing evidence that the baffled probe, when maximally shielded, can provide an accurate measure of the ion temperature.

\section{B. Floating Potential}

Floating potential measurements for orientations of the probe through $360^{\circ}$, show the expected modulation in the amplitude of the floating potential shift, Fig. 13. The observed modulation in Fig. 13 is the result of the designed geometrical restrictions on the collected current. The amplitude of this shift is measured to be approximately $1.5 \mathrm{~V}$. For several probe orientation angles $\left(\theta \approx 10^{\circ}, 350^{\circ}\right)$, maximal shielding of electrons is demonstrated. At maximally shielded probe orientation angles, the floating potential is shifted positively relative to the space potential, producing the increase in modulation amplitude seen in Fig. 13.

Figure 14 shows that the shifting of floating potential as $\mu$ is varied by rotating the probe closely matches the shift predicted by Eq. (7). The solid line Fig. 14 is the floating potential predicted by Eq. (8) with $V_{s} \approx-7.5 \mathrm{~V}$, and $T_{e} \approx 0.23 \mathrm{eV}$, while the filled circles are the experimentally measured values of floating potential. This good agreement between the predicted shift and measured shift reinforces our claim that the baffled Langmuir probe, when optimally shielded, can provide an accurate, real-time measurement of the space potential. 


\section{CONCLUSION}

It has been shown that the addition of ceramic baffles to an ordinary Langmuir probe can result in the suppression of electron current to comparable magnitudes with the ion saturation current, producing a shift in the measured floating potential to within a small fraction of $k_{B} T_{e} / e$ of the space potential. Thus, an optimally shielded baffled probe can be a simple non-emitting electrostatic probe for real-time monitoring of the space potential in magnetized plasma. 


\section{REFERENCES}

[1] F.F. Chen, "Introduction to Plasma Physics and Controlled Fusion.", $2^{\text {nd }}$ ed., Plenum, New York, 1983.

[2] D. Bohm, E.H.S. Burhop, and H.S.W. Massey, in Characteristics of Electrical Discharges in Magnetic Fields, edited by A. Guthrie and R.K. Wakerling, McGraw-Hill, New York, 1949.

[3] B. LaBombard, Phys. Plasmas, 9, 1300 (2002)

[4] N. Bretz, Rev. Sci. Instum., 68, 2927 (1997)

[5] V.I. Demidov, S.V. Ratynskaia, and K. Rypdal, Rev. Sci. Instrum., 73, 3409 (2002)

[6] F.F. Chen, "Probe Diagnostic Techniques", Academic Press Inc., New York, 1965

[7] I. Langmuir and H.M. Mott-Smith, Gen. Electr. Rev., 26, 731 (1923)

[8] H.M. Mott-Smith and I. Langmuir, Phys. Rev., 28, 727 (1926)

[9] J.R. Smith, N. Hershkowitz, and P. Coakley, Rev. Sci. Instrum., 50, 210 (1979)

[10] R.F. Kemp and J.M. Sellen, Rev. Sci. Instrum., 37, 455 (1966)

[11] E.H. Wilson, J. Jeong, and N. Hershkowitz, Rev. Sci. Instrum., 73, 2033 (2002)

[12] I. Katsumata and M. Okazaki, Jpn. J. Appl. Phys., 6, 123 (1967)

[13] S.V. Ratynskaia, V.I. Demidov, and K. Rypdal, Phys. Plasmas, 9, 4135 (2002)

[14] V.I. Demidov, S.V. Ratynskaia, and K. Rypdal, Rev. Sci. Instrum., 73, 3409 (2002)

[15] V.I. Demidov, S.M. Finnegan, M.E. Koepke, and E.W. Reynolds, Rev. Sci. Instrum., 74, 4558 (2003)

[16] V.A. Rozhansky and L.D. Tsendin, "Transport Phenomena in Partially Ionized Plasma.", Taylor and Francis, London, 2001 
[17] V.A. Godyak, in Plasma-Surface Interaction and Processing of Materials, Kluwer, Deventer, (1990), p. 95

[18] T.E. Sheridan and J. Goree, Phys. Rev. E, 50, 2991 (1994)

[19] J.J. Carroll III, M.E. Koepke, M.W. Zintle, and V. Gavrishchaka, Nonlinear Process. Geophys., 10, 131 (2003)

[20] J.J. Carroll III, “Experimental investigation of the IEDD Instability.”, Ph.D. dissertation, Phys. Dept., West Virginia university, Morgantown, WV, (1997)

[21] J.D. Huba, NRL Plasma Formulary, (2000)

[22] Ref. 16, p. 237 


\section{APPENDIX: A}

In this appendix I present a derivation of the equations for collected ion and electron current for the transition region of the current-voltage characteristic. The transition region of the I-V characteristic for a cylindrical probe of radius $R$ and length $L$, in strongly magnetized plasma $\left(\Omega_{e} / \nu_{e n}>>1\right)$, satisfying $L \gg>2 R>L / \sqrt{1+\left(\Omega_{e} / N_{e n}\right)^{2}}$ is modeled using [22]

$$
\varepsilon_{e, i} e V=T_{e, i} \ln \left[\frac{C_{e, i}\left(1-\alpha_{e, i}\right)}{I_{e, i}^{s a t} \alpha_{e, i}}\right]+T_{i, e} \ln \left(1-\alpha_{e, i}\right)
$$

Here, the particle temperature $T_{e, i}$ is in energy units, $V$ is the applied probe voltage relative to the space potential $V_{S}, \varepsilon_{e}=-1, \varepsilon_{i}=+1, \alpha_{e}=I_{e} / I_{e}^{s a t}, \alpha_{i}=I_{i} / I_{i}^{\text {sat }}$ with

$$
\begin{aligned}
& C_{e}=\sqrt{8 \pi} n_{o} e R^{2} \sqrt{T_{e} / m_{e}}, \\
& C_{i}=\sqrt{2} \pi n_{o} e R L \sqrt{T_{i} / m_{i}} .
\end{aligned}
$$

Where, $n_{o}$ is the density and $m_{e, i}$ are the electron and ion masses respectively. Eq. (A.1) is valid for $\varepsilon_{e, i}\left(V_{b}-V_{S}\right)<0$. Solving Eq. (A.1) for $\alpha_{e, i}$,

$$
\begin{gathered}
\varepsilon_{e, i} e V=\ln \left[\left(\frac{C_{e, i}\left(1-\alpha_{e, i}\right)}{I_{e, i}^{s a t} \alpha_{e, i}}\right)^{T_{e, i}}\left(1-\alpha_{e, i}\right)^{T_{i, e}}\right], \\
e^{\varepsilon_{e, i} V}=\left(\frac{C_{e, i}\left(1-\alpha_{e, i}\right)}{I_{e, i}^{s a t} \alpha_{e, i}}\right)^{T_{e, i}}\left(1-\alpha_{e, i}\right)^{T_{i, e}}, \\
\left(1-\alpha_{e, i}\right)^{\frac{T_{i, e}+T_{e, i}}{T_{e, i}}}-\frac{I_{e, i}^{s a t} \alpha_{e, i}}{C_{e, i}} e^{\frac{\varepsilon_{e, i} V}{T_{e, i}}}=0 .
\end{gathered}
$$


For the case of equivalent electron and ion temperatures $\left(T_{e, i}=T_{i, e}=T\right)$, Eq. (A.6) reduces to a quadratic polynomial in $\alpha_{e, i}$.

$$
\alpha_{e, i}^{2}-\alpha_{e, i} 2\left[1+\frac{I_{e, i}^{s a t}}{2 C_{e, i}} e^{\frac{\varepsilon_{e, i} e V}{T}}\right]+1=0
$$

The roots of Eq. (A.7) are

$$
\begin{aligned}
& \alpha_{e, i}=1+\frac{I_{e, i}^{s a t}}{2 C_{e, i}} e^{\frac{\varepsilon_{e, i} e V}{T}} \pm \frac{1}{2} \sqrt{4\left(1+\frac{I_{e, i}^{s a t}}{2 C_{e, i}} e^{\frac{\varepsilon_{e, i} e V}{T}}\right)^{2}-4}, \\
& \alpha_{e, i}=1+\frac{I_{e, i}^{s a t}}{2 C_{e, i}} e^{\frac{\varepsilon_{e, i} e V}{T}} \pm \frac{1}{2} \sqrt{4 \frac{I_{e, i}^{s a t}}{C_{e, i}} e^{\frac{\varepsilon_{e, i} e V}{T}}\left(1+\frac{I_{e, i}^{s a t}}{4 C_{e, i}} e^{\frac{\varepsilon_{e, i} V}{T}}\right.}, \\
& \alpha_{e, i}=1+\frac{I_{e, i}^{s a t}}{2 C_{e, i}} e^{\frac{\varepsilon_{e, i} V}{T}} \pm \sqrt{\frac{I_{e, i}^{s a t}}{C_{e, i}}} e^{\frac{\varepsilon_{e, e} V}{2 T}}\left(1+\frac{I_{e, i}^{s a t}}{4 C_{e, i}} e^{\frac{\varepsilon_{e, i} e V}{T}}\right)^{\frac{1}{2}}
\end{aligned}
$$

The physical root of Eq. (A.10) is the negative root. Substituting into Eq. (A.10) the definitions for $\alpha_{e, i}, C_{e, i}, \varepsilon_{e, i}$, separating into separate equations for ions and electrons, and solving for $I_{e}$ and $I_{i}$ we obtain,

$$
\begin{gathered}
I_{e}=I_{e}^{s a t}+\frac{\left(I_{e}^{s a t}\right)^{2}}{\sqrt{32 \pi} n_{o} e R^{2} v_{i e}} e^{-\frac{e V}{T}}-I_{e}^{s a t} \sqrt{\frac{I_{e}^{s a t}}{\sqrt{8 \pi} n_{o} e R^{2} v_{T e}}} e^{-\frac{e V}{2 T}}\left[1+\frac{I_{e}^{s a t}}{\sqrt{128 \pi} n_{o} e R^{2} v_{T e}} e^{-\frac{e V}{T}}\right]^{1 / 2} \\
I_{i}=I_{i}^{\text {sat }}+\frac{\left(I_{i}^{\text {sat }}\right)^{2}}{\sqrt{8} \pi n_{o} e R L v_{T i}} e^{\frac{e V}{T}}-I_{i}^{s a t} \sqrt{\frac{I_{i}^{s a t}}{\sqrt{2} \pi n_{o} e R L v_{T i}}} e^{\frac{e V}{2 T}}\left[1+\frac{I_{i}^{s a t}}{\sqrt{32} \pi n_{o} e R L v_{T i}} e^{\frac{e V}{T}}\right]^{1 / 2} .
\end{gathered}
$$




\section{APPENDIX: B}

In this appendix, I present a derivation of Eq. (4). When the probe is rotated to maximally shield electrons from the collecting surface, the electron saturation current is reduced by a multiplicative factor of $v_{e n} / \Omega_{e}$ to correct for cross-field diffusive effects ( $v_{e n}$ is the electron-neutral collision frequency, and $\Omega_{e}$ is the electron gyrofrequency).

$$
I_{e, 0^{\circ}}^{s a t}=\frac{v_{e n}}{\Omega_{e}} I_{e, 90^{\circ}}^{s a t}
$$

It follows Eq. (B.1) that

$$
1=\frac{\Omega_{e}}{\mathrm{v}_{e n}} \frac{I_{e, 0^{\circ}}^{s a t}}{I_{e, 90^{\circ}}^{s a t}}
$$

Substituting into Eq. (B.2) expressions for $\Omega_{e}$, and $v_{e n}$ from [21], we obtain

$$
1=\frac{1.76 \times 10^{7} B(\mathrm{rad} / \mathrm{sec})}{2.91 \times 10^{-6} n_{o} \ln \Lambda T_{e}^{-3 / 2}\left(\mathrm{sec}^{-1}\right)} \cdot \frac{\mathrm{cm}^{-3}}{\mathrm{G} \cdot \mathrm{eV}^{3 / 2}} \cdot \frac{I_{e, 0^{\circ}}^{s a t}}{I_{e, 90^{\circ}}^{s a t}}
$$

Here, $B$ is magnetic field in gauss, $n_{o}$ is density in $\mathrm{cm}^{-3}, T_{e}$ is electron temperature in $\mathrm{eV}$, and $\ln \Lambda$ is the Coulomb logarithm. In a Q-machine plasma, the Coulomb logarithm can be approximated as $\ln \Lambda \approx 10$. Solving Eq. (B.3) for $n_{o}$, yields

$$
n_{o}=6.05 \times 10^{11} B T_{e}^{3 / 2}(\mathrm{rad}) \cdot \frac{\mathrm{cm}^{-3}}{\mathrm{G} \cdot \mathrm{eV}^{3 / 2}} \cdot \frac{I_{e, 0^{\circ}}^{\mathrm{sat}}}{I_{e, 90^{\circ}}^{s a t}}
$$

Converting magnetic field from Gauss to Kilo-Gauss, and density from $\mathrm{cm}^{-3}$ to $\mathrm{m}^{-3}$, Eq. (B.4) becomes,

$$
n_{o}=3.8 \times 10^{21} B T_{e}^{3 / 2} \cdot \frac{\mathrm{m}^{-3}}{\mathrm{kG} \cdot \mathrm{eV}^{3 / 2}} \cdot \frac{I_{e, 0^{\circ}}^{s a t}}{I_{e, 90^{\circ}}^{s a t}}
$$




\section{TABLE}

\section{WVU Q-Machine Operating Parameters}

$$
\begin{aligned}
& 1(\mathrm{kG})<B<3(\mathrm{kG}) \\
& n \approx 10^{9} \mathrm{~cm}^{-3} \\
& T_{e} \approx 0.2 \mathrm{eV} \\
& T_{i} \approx 0.2 \mathrm{eV} \\
& \Omega_{e} \approx 10^{10} \mathrm{~Hz} \\
& \omega_{p e} \approx 300 \mathrm{MHz} \\
& \omega_{p i} \approx 1 \mathrm{MHz} \\
& \rho_{e} \approx 4 \times 10^{-4} \mathrm{~cm} \\
& \lambda_{D} \approx 0.01 \mathrm{~cm} \\
& P_{n}<10^{-6} \text { Torr }
\end{aligned}
$$

\begin{tabular}{|c|c|c|c|}
\hline & $\underline{\mathrm{Na}^{+}}$ & $\underline{\mathrm{K}^{+}}$ & $\underline{B a}^{+}$ \\
\hline$\Omega_{i}(1 \mathrm{kG}):$ & 67 & 39 & 11 \\
\hline $\mathrm{V}_{\mathrm{Ti}}(0.2 \mathrm{eV})$ & 915 & 700 & 380 \\
\hline$\rho_{i}(1 \mathrm{kG}):$ & 2.2 & 2.8 & 5.3 \\
\hline
\end{tabular}

Table 1: Table of operational parameters for the WVU Q-machine. 


\section{FIGURES}

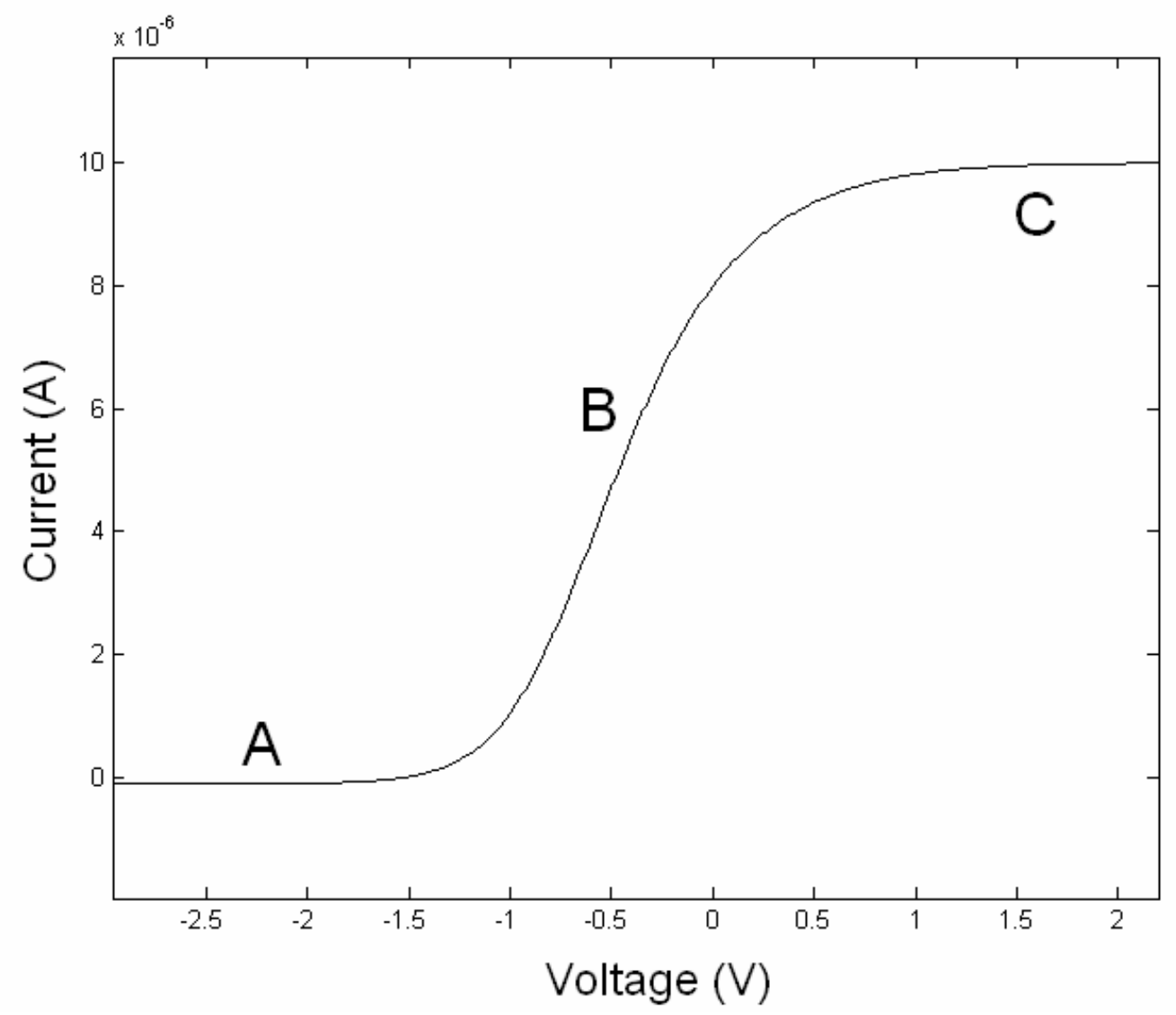

Figure 1: Typical probe current-voltage characteristic. Region $A$ is ion saturation, $B$ is the transition region, and $C$ is electron saturation. 


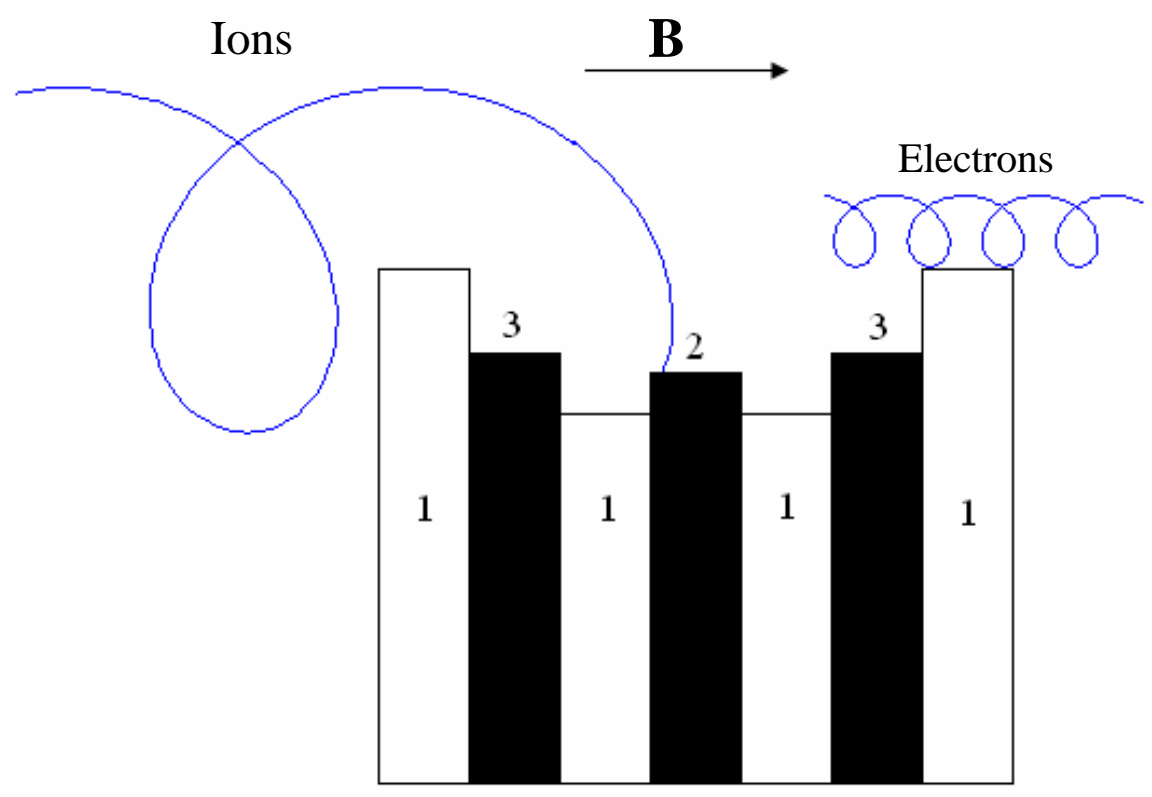

Figure 2: Sketch of Katsumata probe. (1) Ceramic insulation; (2) central electrode; (3) guard electrodes. 

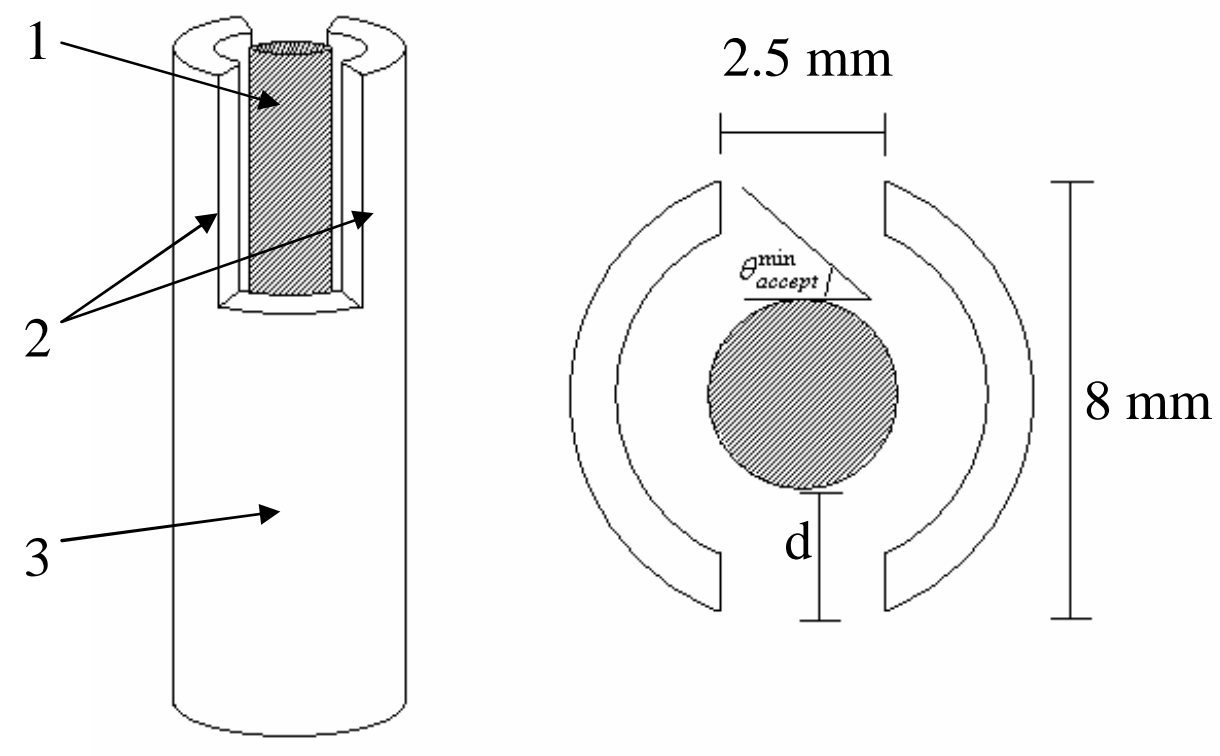

Figure 3a: Sketch of the baffled Langmuir probe. (1) Tungsten wire probe tip; (2) ceramic baffles (masks); (3) ceramic shielding.

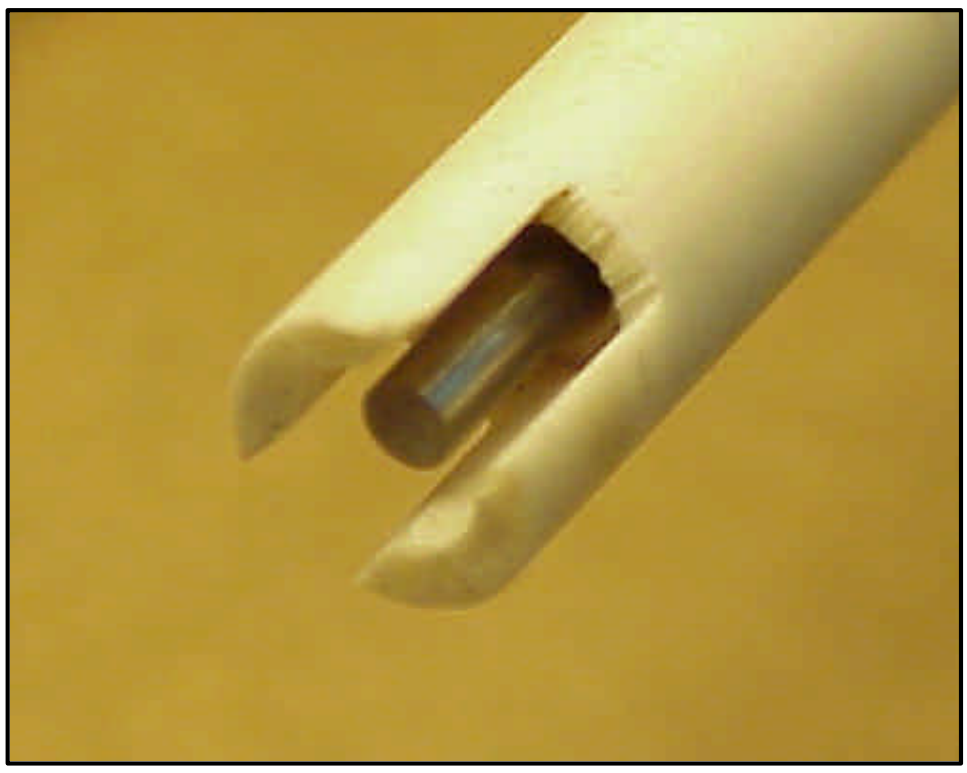

Figure 3b: Picture of the baffled Langmuir probe. 


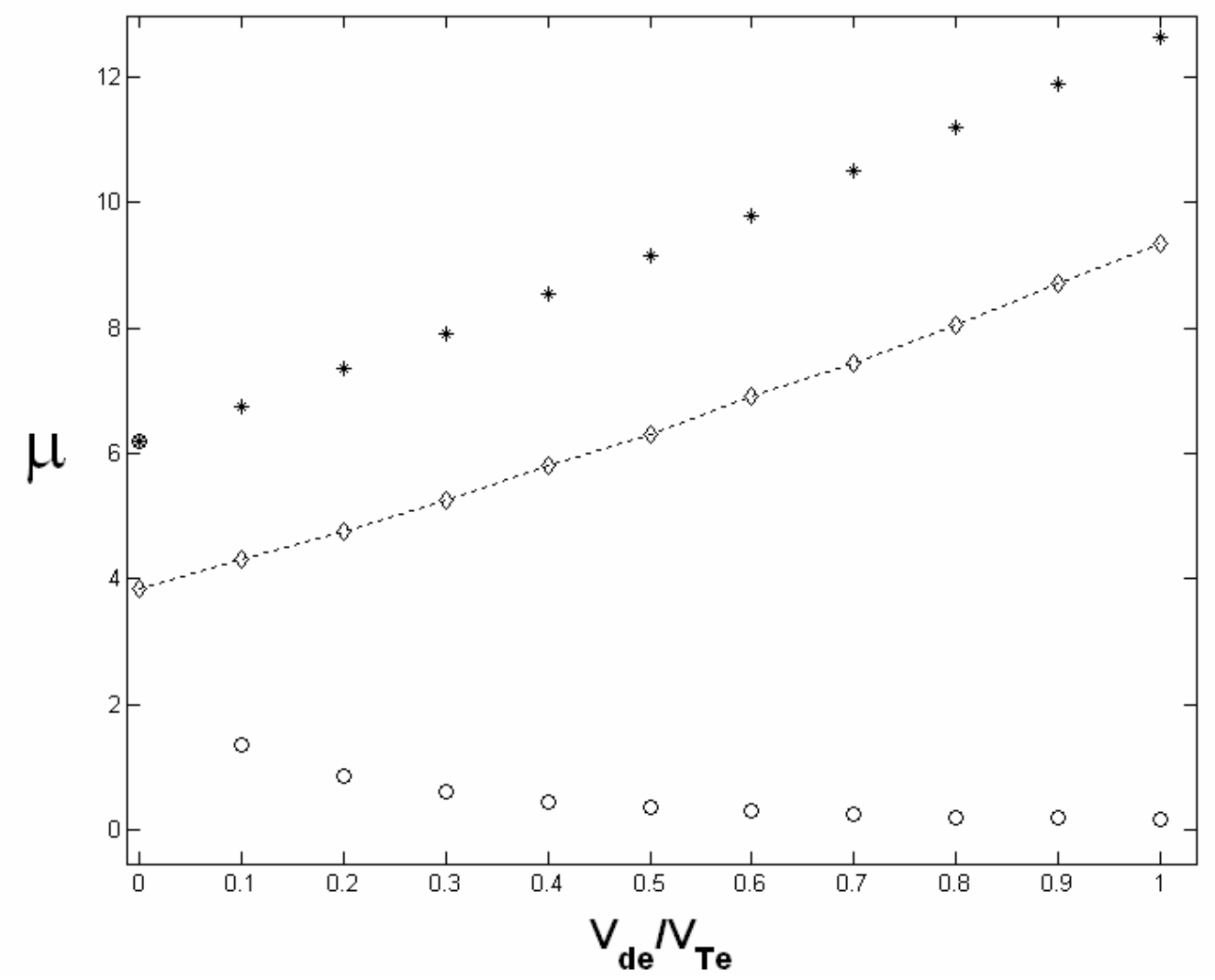

Figure 4: Numerical solutions for dimensionless coefficient $\mu=e\left(V_{S}-V_{f}\right) / T_{e}$, as a function electron drift speed. The upper curve (asterisks), is the case of zero ion drift $\left(v_{d i}=0\right)$. The middle curve (diamonds), represents the experimental conditions for experiments with baffled Langmuir probe $\left(v_{d i}=3 v_{T i}\right)$. The bottom curve (circles), is for bulk-plasma flow $\left(v_{d e}=v_{d i}\right)$. 


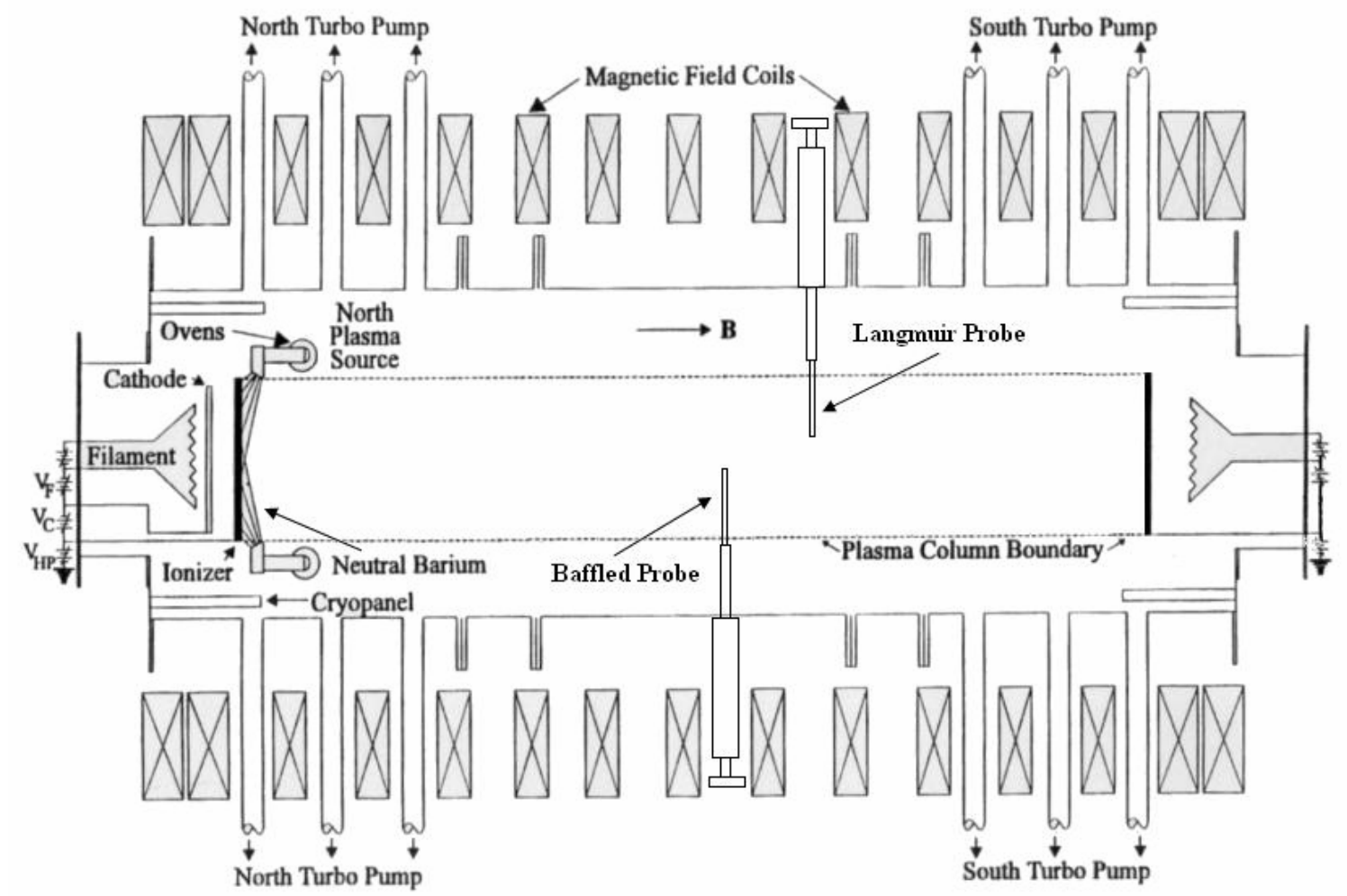

Figure 5: Schematic of WVU Q-machine [20]. Each block symbol for the magnetic field coils represents a set of three coils in contact with each other, except for the outermost symbols, which represent a single coil. 


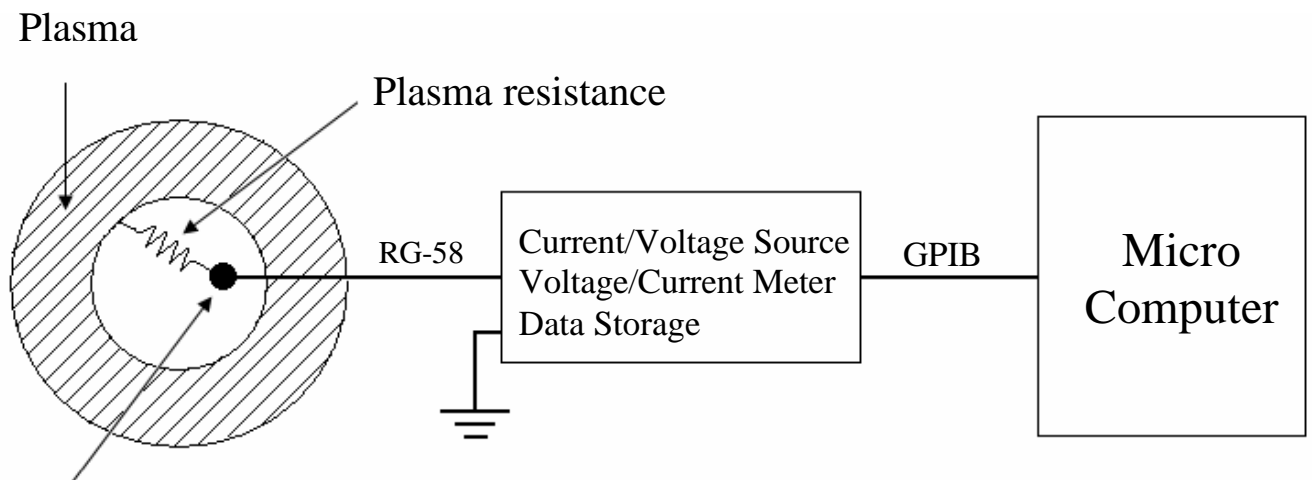

Probe tip

Figure 6: Electric circuit diagram for measuring probe I-V characteristics. The probes voltage and current are measured/sourced by a Keithley 2400 Source Meter. 


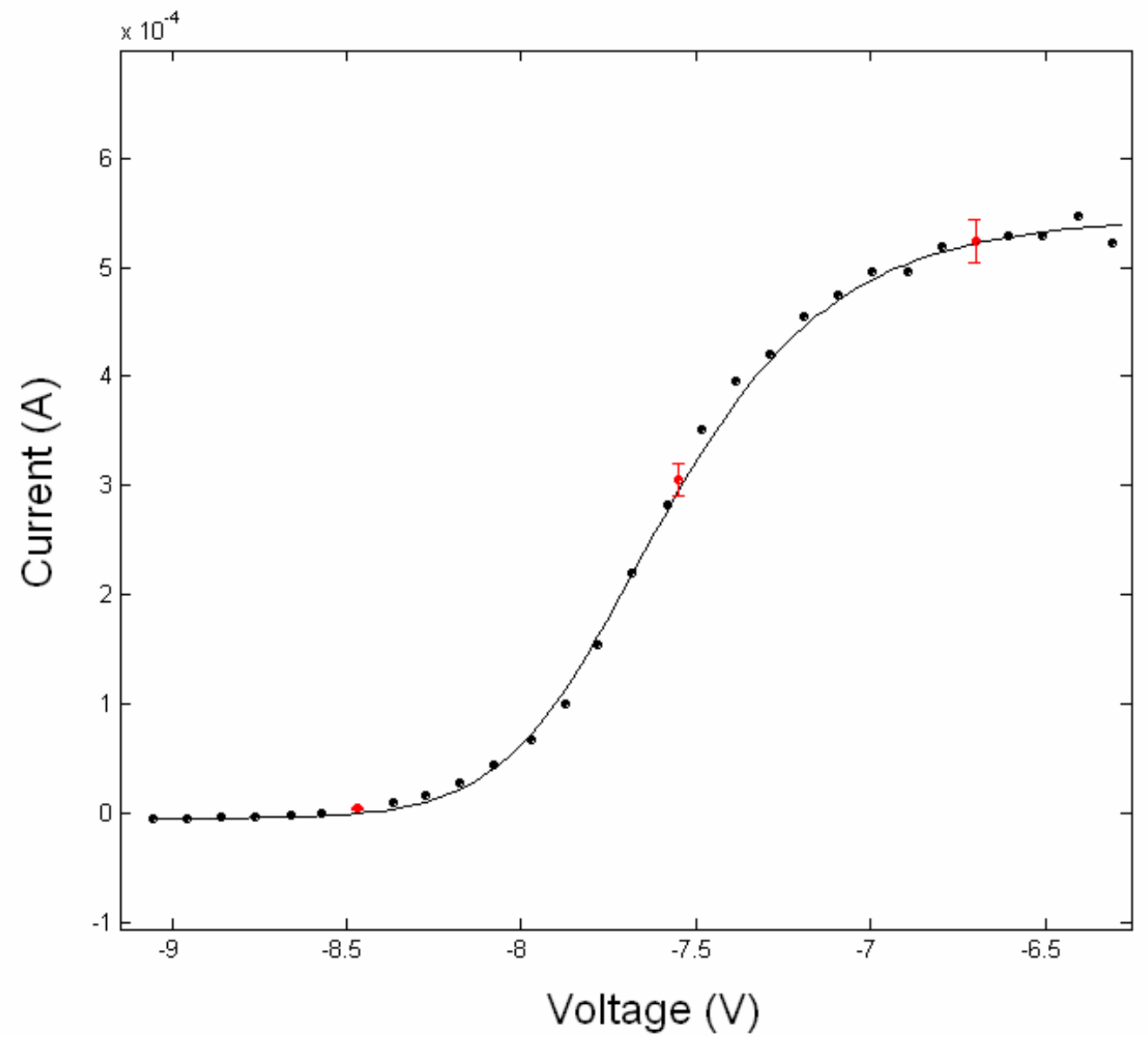

Figure 7: Model, Eqs. $(3,4)$, of baffled probe characteristic (solid line) overlayed with measured characteristic (points) for probe orientation angle $\theta \approx 90^{\circ}$, at $B=3 \mathrm{kG}$. The plasma parameters obtained from the model are: $n_{o}=3 \times 10^{15} \mathrm{~m}^{-3}, T_{i}=T_{e}=0.17 \mathrm{eV}$, and $V_{S}=-7.5 \mathrm{~V}$. 


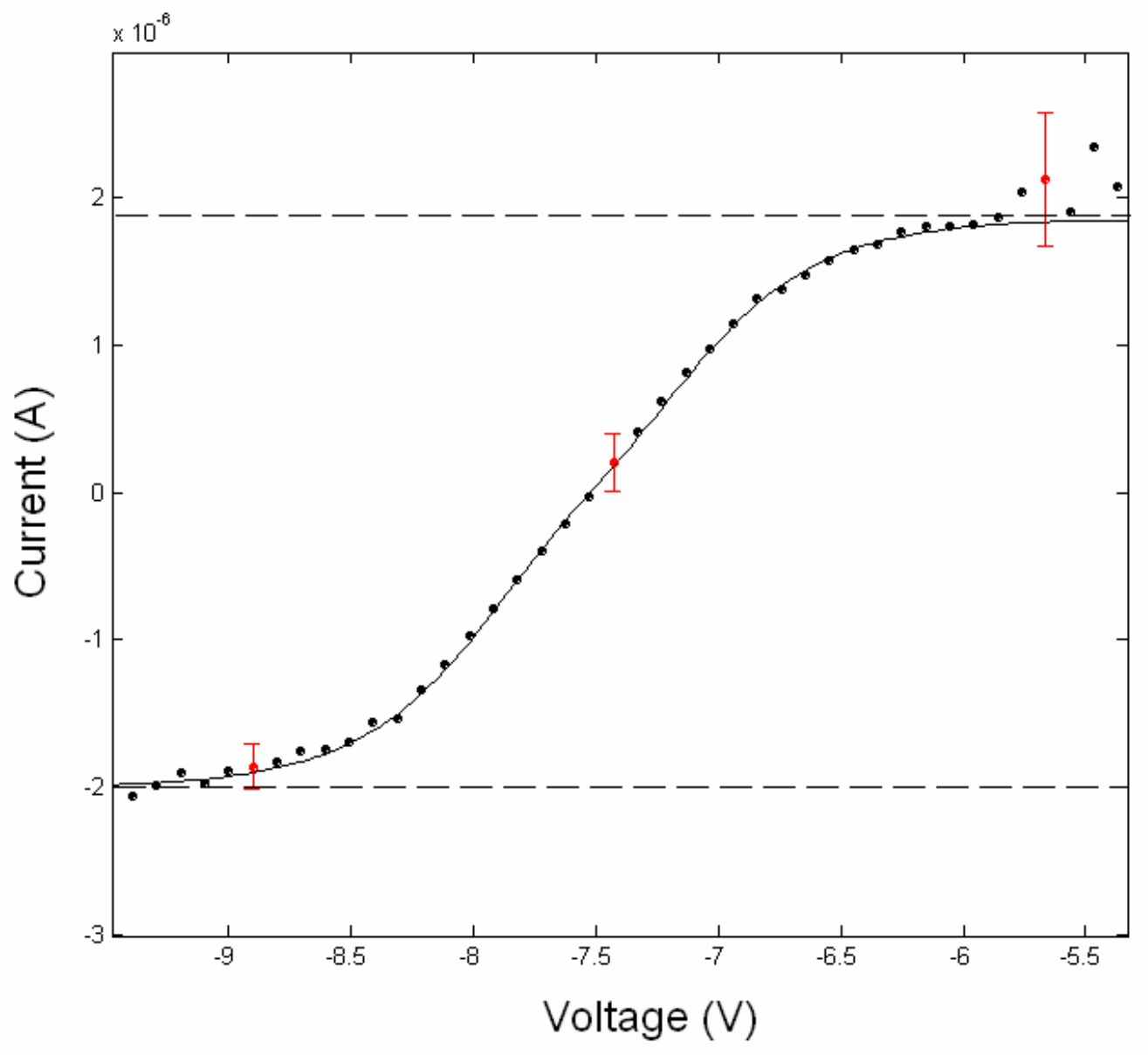

Figure 8: Model, Eqs. (3,4), of baffled probe characteristic (solid line) overlayed with measured characteristic (points) for probe orientation angle $\theta \approx 30^{\circ}$, at $B=3 \mathrm{kG}$. The plasma parameters obtained from the model are: $n_{o}=3 \times 10^{15} \mathrm{~m}^{-3}, T_{i}=T_{e}=0.17 \mathrm{eV}$, and $V_{S}=-7.45 \mathrm{~V}$. 


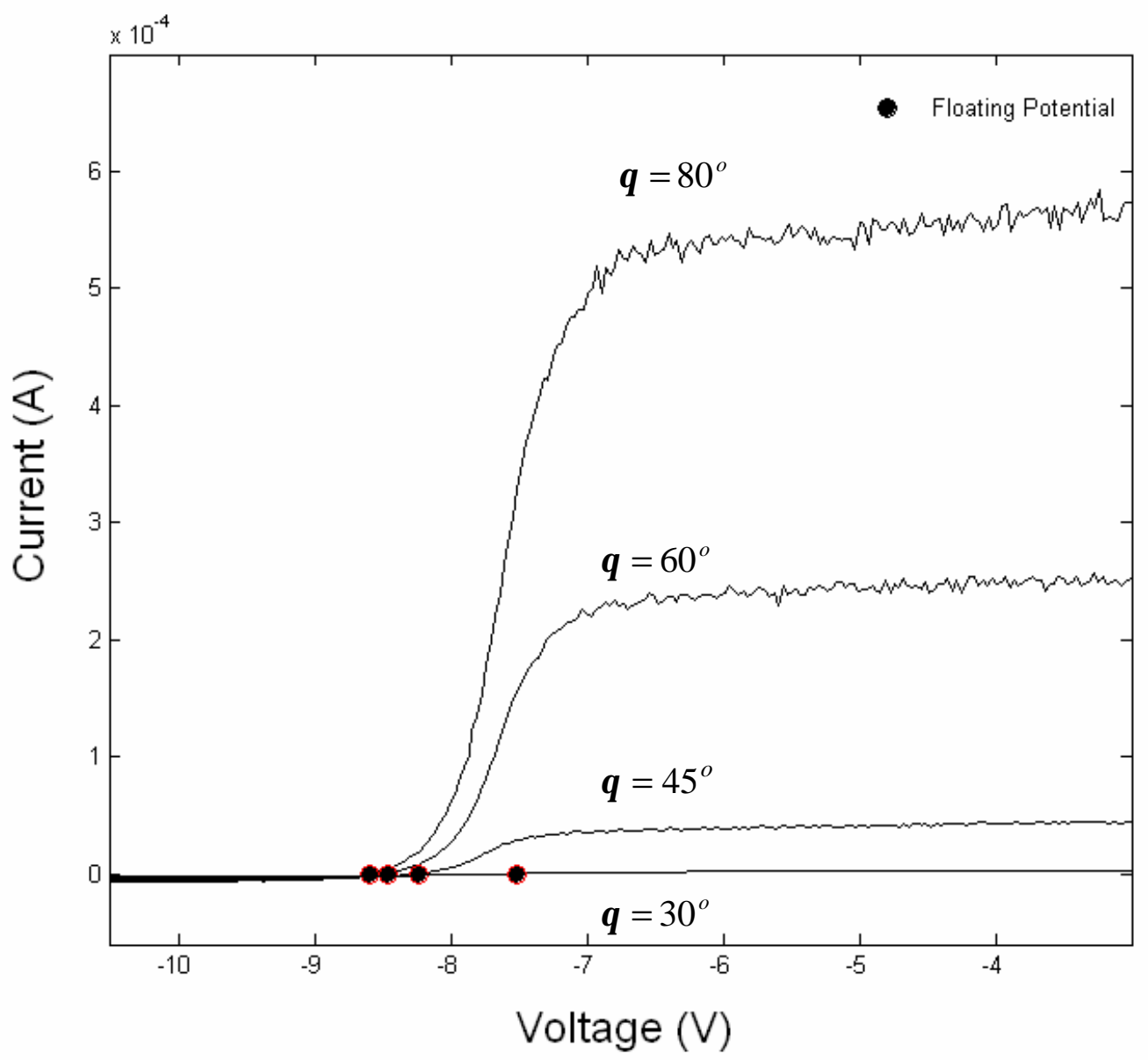

Figure 9: Measured current voltage characteristics for several baffled probe orientation angles $\theta=30^{\circ}, 45^{\circ}, 60^{\circ}$, and $80^{\circ}$, at $B=3 \mathrm{kG}$. The filled circles indicate floating potential, $V_{f}$. 


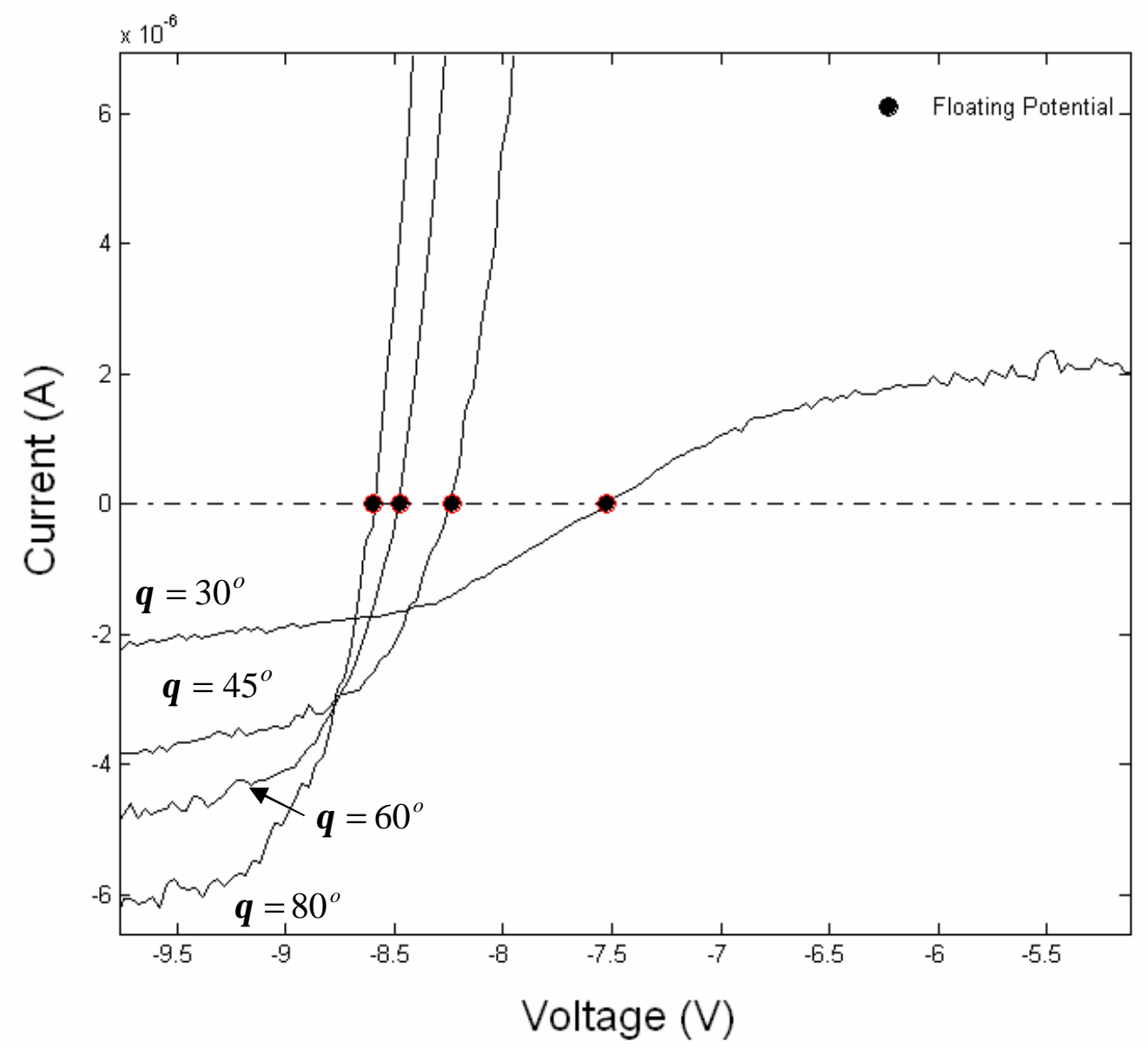

Figure 10: Enlarged view of the zero crossing points from Fig. 9, showing more clearly the shift in the floating potential. 


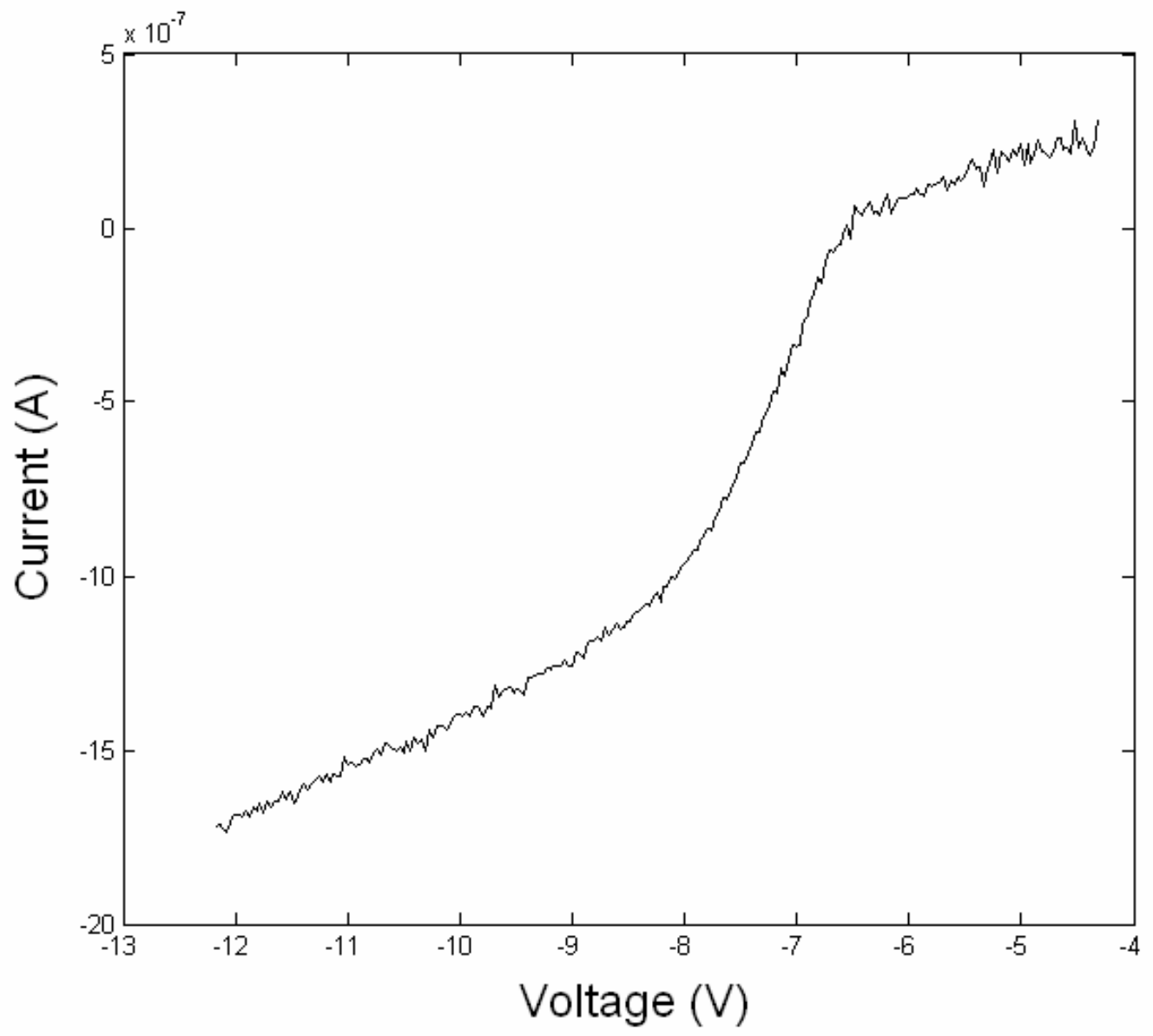

Figure 11: I-V characteristic obtained from baffled Langmuir probe with maximally shielded probe orientation $\theta \approx 10^{\circ}$, at $B=3 \mathrm{kG}$. 


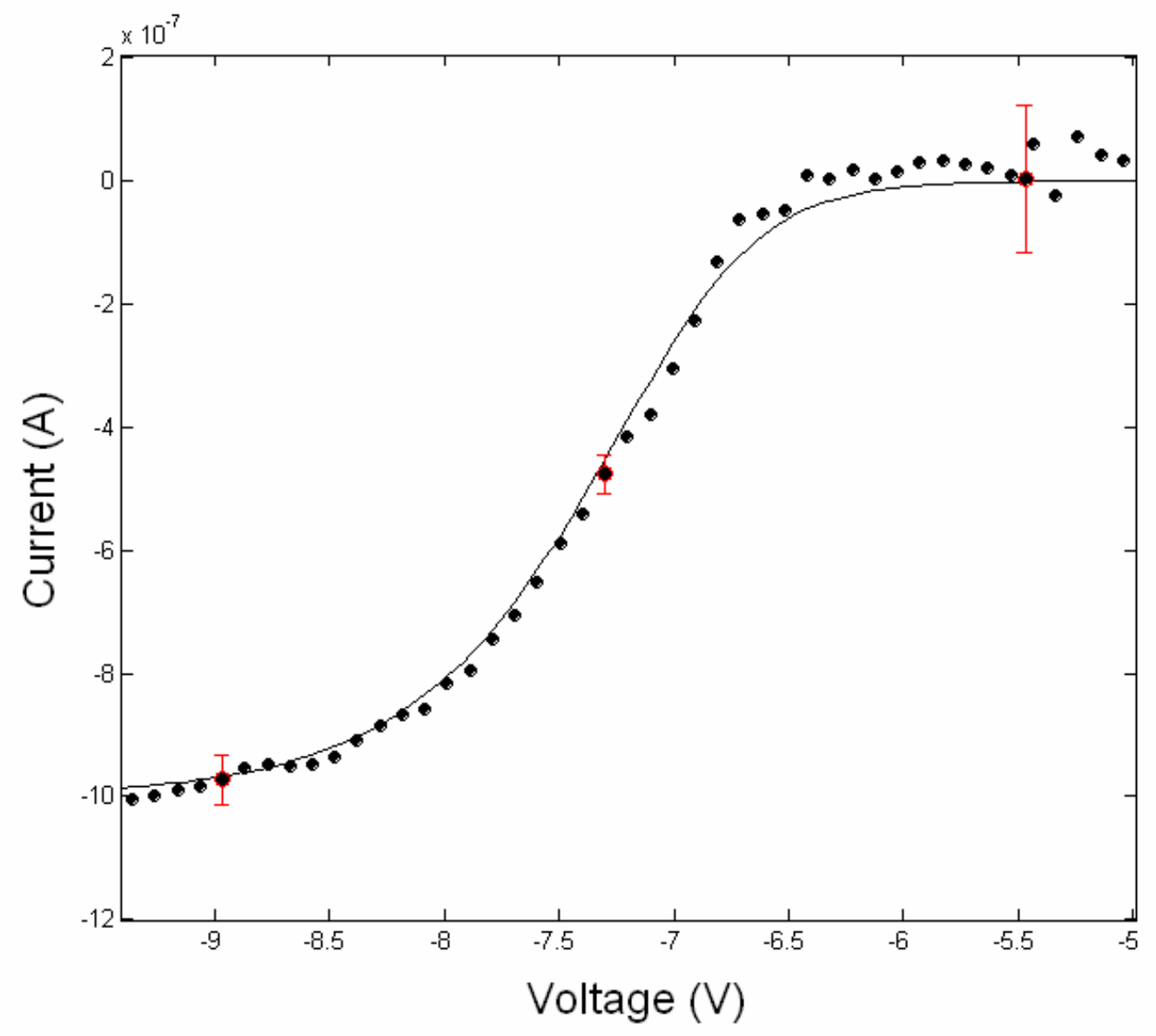

Figure 12: Model, Eq. (2), of baffled probe characteristic (solid line) overlayed with the processed baffled probe characteristic of Fig. 11 (points) for probe orientation angle $\theta \approx 10^{\circ}$, at $B=3 \mathrm{kG}$. The ion temperature and space potential obtained from the model are: $T_{i}=0.19 \mathrm{eV}$, and $V_{S}=-7.48 \mathrm{~V}$. 


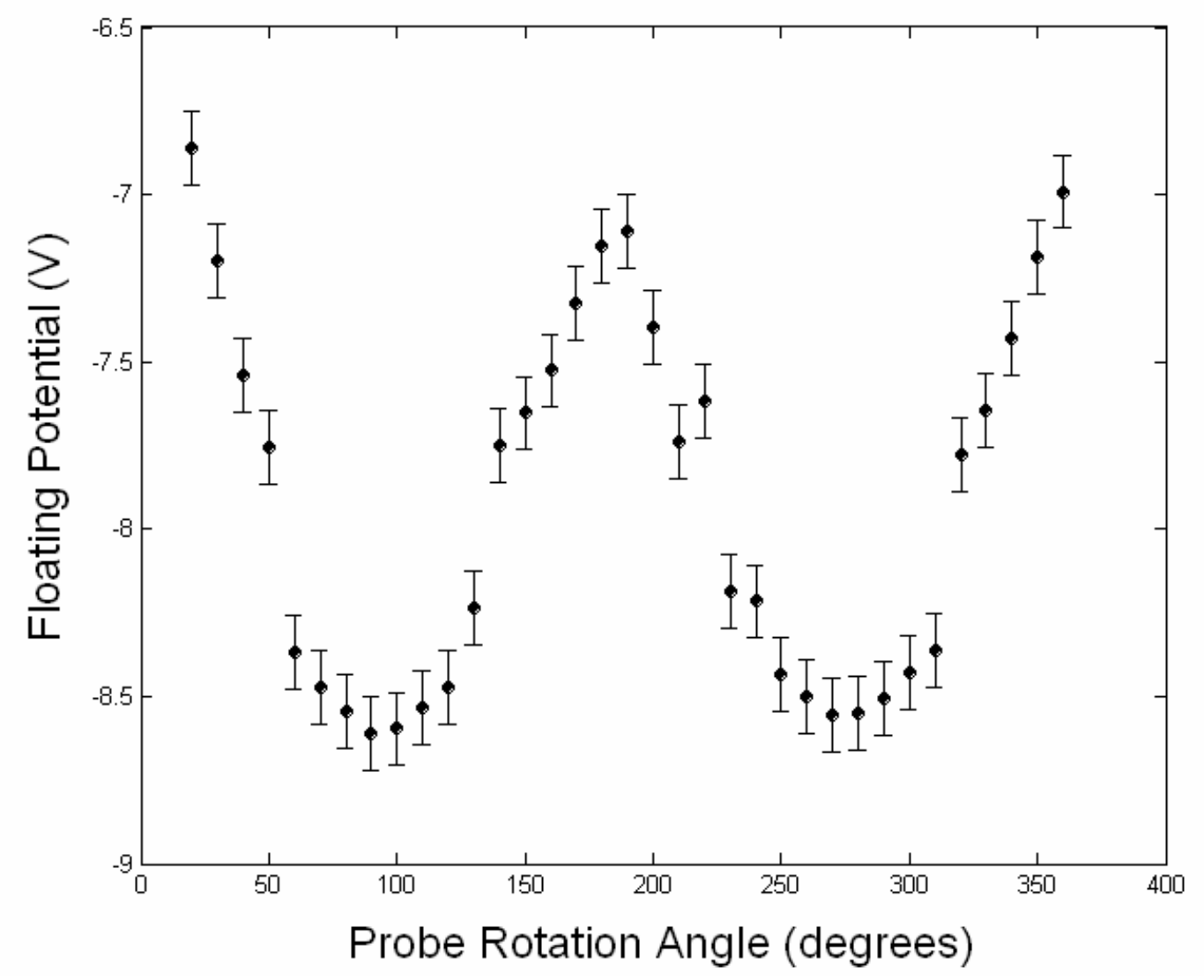

Figure 13: Measured floating potential as the baffled probe orientation is incremented through $360^{\circ}$, at $B=3 \mathrm{kG}$. 


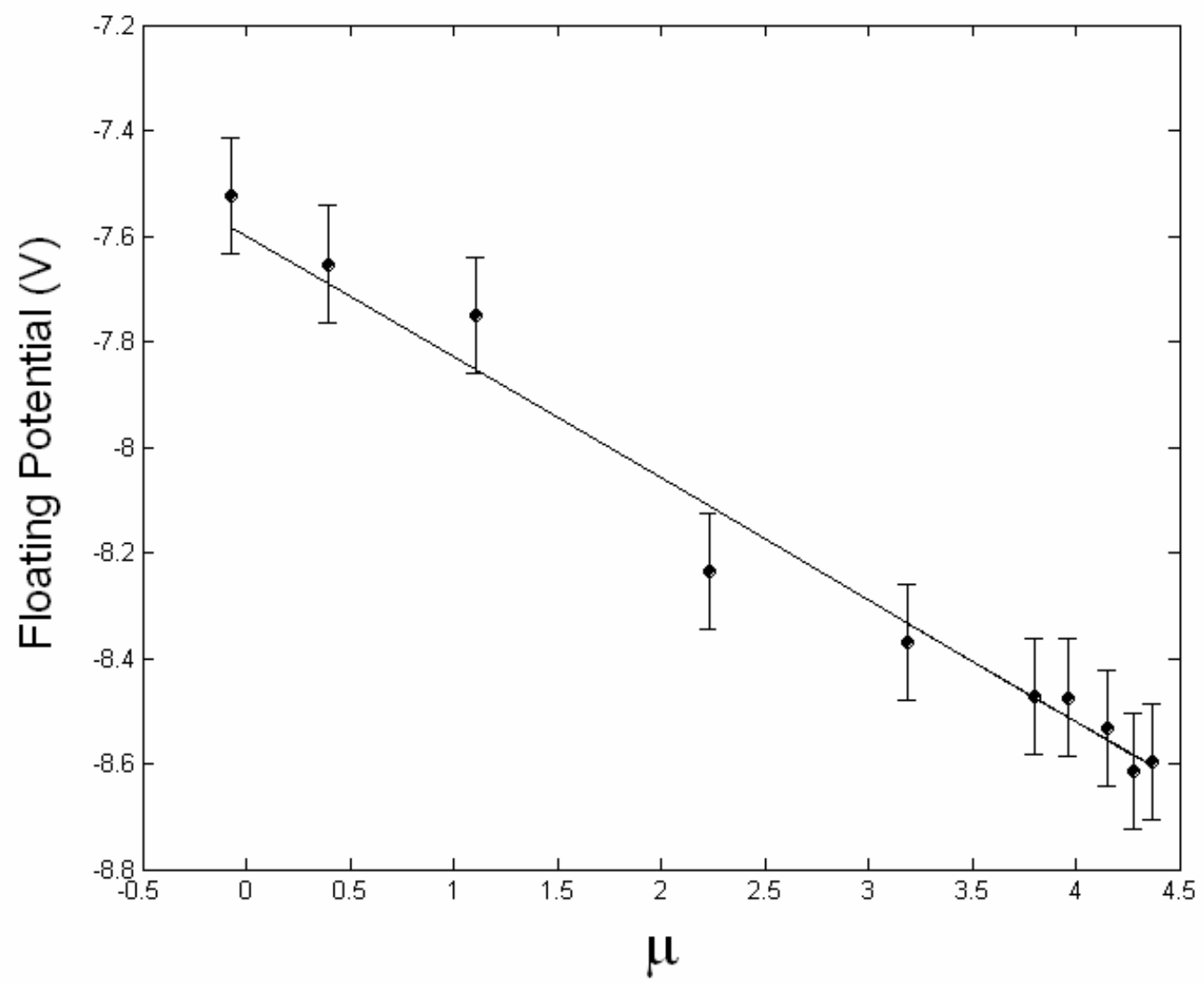

Figure 14: Measured values of floating potential (dots) as the collected electron current is suppressed for $B=3 \mathrm{kG}$. For $T_{e} \approx 0.23 \mathrm{eV}$, the model, Eq. (7), gives the solid line, implying that the space potential is $V_{S} \approx-7.5 \mathrm{~V}$. 